\title{
The Development of Cladribine Tablets for the Treatment of Multiple Sclerosis: A Comprehensive Review
}

\author{
Kottil Rammohan ${ }^{1} \cdot$ Patricia K. Coyle $^{2} \cdot$ Elke Sylvester $^{3} \cdot$ Andrew Galazka $^{3} \cdot$ Fernando Dangond ${ }^{4} \cdot$ Megan Grosso $^{5}$. \\ Thomas P. Leist ${ }^{6}$
}

Published online: 28 November 2020

(C) The Author(s) 2020

\begin{abstract}
Cladribine is a purine nucleoside analog initially developed in the 1970 s as a treatment for various blood cancers. Due to the molecule's ability to preferentially reduce T and B lymphocytes, it has been developed into an oral formulation for the treatment of multiple sclerosis (MS). The unique proposed mechanism of action of cladribine allows for the therapy to be delivered orally over two treatment-week cycles per year, one cycle at the beginning of the first month and one cycle at the beginning of the second month of years 1 and 2, with the potential for no further cladribine treatment required in years 3 and 4. This review summarizes the clinical development program for cladribine tablets in patients with MS, including the efficacy endpoints and results from the 2-year phase III CLARITY study in patients with relapsing-remitting MS (RRMS), the 2-year CLARITY EXTENSION study, and the phase III ORACLE-MS study in patients with a first clinical demyelinating event at risk for developing MS. Efficacy results from the phase II ONWARD study, in which cladribine tablets were administered as an add-on to interferon- $\beta$ therapy in patients with RRMS, are also summarized. A review of all safety data, including lymphopenia, infections, and malignancies, is provided based on data from all trials in patients with MS, including the initial parenteral formulation studies. Based on these data, cladribine tablets administered at $3.5 \mathrm{mg} / \mathrm{kg}$ over 2 years have been approved across the globe for various forms of relapsing MS.
\end{abstract}

\section{Introduction}

Multiple sclerosis (MS) is a chronic, inflammatory, immunemediated demyelinating and neurodegenerative disease of the central nervous system (CNS). It is one of the most

Enhanced Digital Features To view enhanced digital features for this article, go to https://doi.org/10.1007/s40265-020-01422-9

Kottil Rammohan

krammohan@med.miami.edu

1 Multiple Sclerosis Center, University of Miami, Miami, FL, USA

2 Multiple Sclerosis Comprehensive Care Center, Stony Brook University, Stony Brook, NY, USA

3 Merck KGaA, Darmstadt, Germany

4 EMD Serono Research \& Development Institute, Inc., Billerica, MA, USA, an affiliate of Merck KGaA, Darmstadt, Germany

5 EMD Serono, Inc., Rockland, MA, USA, an affiliate of Merck KGaA, Darmstadt, Germany

6 Comprehensive MS Center, Jefferson University, Philadelphia, PA, USA common causes of serious neurological disability in young adults, and one of the most prevalent neurological disorders in the world [1]. In 2016, the estimated global prevalence of MS was 2.2 million, an increase of $10.4 \%$ from the age-standardized MS prevalence in 1990 [2]. Among the more than 2 million people with MS, more than 900,000 are thought to reside in the United States (US) [3]. About 85\% of patients with MS present with relapsing-remitting MS (RRMS), which is characterized by periodic acute exacerbations of disease activity (relapses) punctuated by periods of clinical stability. Relapses may be associated with partial or complete recovery [4].

MS is associated with poor health-related quality of life and can have a profound effect on social functioning, employment status, and healthcare costs $[5,6]$. The mean age at onset of symptoms is 30 years, and approximately $75 \%$ of patients are female [7]. Therefore, many patients are women of childbearing age, and MS can impact family planning due to risks associated with treatments that may affect pregnancy [8]. While there are no adequately controlled studies of disease-modifying drugs (DMDs) and pregnancy, there is a significant body of evidence on the safety of DMDs during pregnancy, generated primarily 


\section{Key Points}

Multiple sclerosis (MS) is a neurodegenerative disease that affects more than 2 million people globally and is associated with poor quality of life. MS involves an aberrant immune system attacking the central nervous system, and disease-modifying drugs are thought to act by suppressing or modulating the immune system.

Cladribine tablets are the first oral therapy with a shortcourse, limited cycle dosing schedule approved for patients with relapsing forms of MS (RMS). In clinical studies, cladribine tablets have demonstrated efficacy in patients across the RMS spectrum.

The safety profile of cladribine tablets monotherapy at the recommended dosage of $3.5 \mathrm{mg} / \mathrm{kg}$ includes data from $>3700$ patient-years of cladribine exposure at this dose, and from $>2200$ patient-years of placebo exposure in clinical trials. The most common adverse events reported with cladribine tablets include headaches and lymphopenia. Additional adverse events examined include malignancy and infections.

from clinical experience and pregnancy registries. Large interferon (IFN) $-\beta$ registry studies have found no evidence for differences in infant size [9], congenital anomalies, or miscarriages [10], and recently updated IFN- $\beta$ Summaries of Product Characteristics recommend to continue treatment during pregnancy and while breastfeeding if clinically needed [11, 12]. Glatiramer acetate is also generally considered to be safe for use during pregnancy $[13,14]$. However, the labels for the majority of DMDs for patients with MS either state to use 'only if clearly needed' [15], to avoid these therapies unless the benefits outweigh the risks [16-19], or not to use at all, and a washout period is recommended prior to pregnancy [20-26]. Longitudinal studies indicate that life expectancy is shorter for patients with MS compared with the general population (approximately 7 years shorter in a Norwegian population studied over a 60 -year period) [27], but rising prevalence without parallel changes in incidence, and a shift in peak age towards older age groups, suggest that survival is improving (based on Canadian data collected over 2 decades) [28]. An aging MS population may be associated with significant disability; in a self-reporting postal survey conducted in a Canadian cohort of MS patients aged $>55$ years who had been living with MS for a mean of approximately 33 years, $28 \%$ either required a wheelchair or were bedridden [29].

Lymphocytes play a central role in the pathogenesis of MS, with the actions of both B and T cells in the periphery and in the CNS implicated from an early stage in the disease process. Immune cells activated in the periphery enter the CNS, facilitated by chemokines [30, 31]. Autoreactive T cells are present in acute CNS lesions in early MS [30, 32]; their reaction to myelin protein-derived antigens [32] contributes to direct cytotoxic effects and stimulation of macrophages $[31,33]$. B cells have a role in the proliferation and reactivation of $\mathrm{T}$ cells, acting as antigen-presenting cells, and fully differentiated B cells further contribute to demyelination via the production of antibodies to myelin by plasma cells [30, 31, 33, 34]. Thus, the combined actions of T cells, $\mathrm{B}$ cells, and macrophages contribute to demyelination and axonal damage, triggering neurodegenerative processes from disease onset [30,31]. Later in the course of the disease, chronic CNS inflammation drives ongoing neurodegeneration, possibly via neurotoxic inflammatory mediators produced by activated microglia and astrocytes [32].

Treatment options for relapsing forms of MS (RMS) comprise a number of immunosuppressive and immunomodulatory agents. The first DMD, IFN- $\beta-1 b$, was approved by the US Food and Drug Administration (FDA) for RMS in 1993 [19] and by the European Medicines Agency (EMA) in 1995 [35]. Alternative forms of IFN- $\beta$ (subcutaneous [SC] and intramuscular [IM] IFN- $\beta-1 \mathrm{a}$ ) and glatiramer acetate entered the market between 1996 and 2002, becoming standard treatment over the ensuing years [36]. The introduction of natalizumab, a recombinant monoclonal antibody against cell adhesion molecule $\alpha 4$-integrin [23] (initially approved in 2004, withdrawn from the market, then reintroduced in 2006 [37]), marked a shift in the treatment paradigm for MS [38]. While this molecule was perceived to be more effective than the IFNs and glatiramer acetate [39], it is associated with greater risks, including progressive multifocal leukoencephalopathy (PML), which is rare but carries significant morbidity and a mortality rate of approximately $23 \%$ [40]. After a span of nearly 20 years of injectable therapies, oral DMDs became available. While patients have generally preferred oral DMDs over injections when given the choice [41], most approved oral DMDs, including fingolimod, teriflunomide, dimethyl fumarate and siponimod, require regular and ongoing dosing once- or twice-daily [20-22].

More recently, therapies with different hypothesized mechanisms of action (MOA) that require less frequent dosing have become available. Ocrelizumab is an anti-CD20 antibody, administered via intravenous (IV) infusion every 6 months (after the initial dose, which is split across two infusions 2 weeks apart) [25, 42]. Alemtuzumab is an antiCD52 antibody with an infrequent dosing regimen, involving infusions over a course of 5 days in year 1 , followed by 3 days in year 2, with further 3-day courses administered as needed thereafter, separated by intervals of at least 12 months [24, 43]. Both antibodies are thought to deplete lymphocytes via cytolysis and complement-mediated lysis, with different profiles based on expression of their respective 
target antigens on B cells, T cells, and other immune cells [24, 25, 44-46].

Cladribine tablets are the first oral therapy with an infrequent dosing schedule, administered in two yearly treatment courses, each divided into two treatment cycles comprising 4-5 days of treatment $[12,26]$. Cladribine tablets are thought to exert their clinical effects via a transient reduction of selective lymphocyte subtypes, followed by a recovery period during which cell numbers return to the normal range $[47,48]$. While immune function is restored as cell numbers recover, cell subtype ratios are thought to be altered, resulting in a reduction in autoreactive lymphocytes [47-49]. Thus, a short dosing period is thought to achieve sustained effects on lymphocytes that persist for an extended period after the treatment period has ended.

Cladribine tablets have been approved worldwide by many different regulatory authorities, including the EMA in 2017 [50] and the FDA in 2019 [51]. In this review, we provide an overview of the development of cladribine tablets as a therapy for patients with MS, from initial discovery and development of the molecule to its putative MOA in MS. We also review the pertinent efficacy data from clinical studies, and an integrated safety analysis of $>3700$ patient-years' clinical trial experience with cladribine tablets monotherapy at the recommended dosage.

\subsection{Discovery and Development}

Cladribine (2-chlorodeoxyadenosine [2-CdA]) was first synthesized nearly 50 years ago [52] (Fig. 1). It is a synthetic purine nucleoside analog of deoxyadenosine that was developed to selectively target lymphocytes in lymphoproliferative diseases (e.g. hairy cell leukemia) and autoimmune disorders [53-55]. The design of cladribine was inspired by the consequences of adenosine deaminase (ADA) deficiency in children $[55,56]$. The selective vulnerability of lymphocytes in this autosomal recessive genetic disorder was described by Carson and colleagues as resulting from the preferential accumulation of cytotoxic deoxyadenosine nucleotides in lymphocytes, causing lymphocytopenia [54, 57]. Based on this understanding, several nucleoside analogs were synthesized, including cladribine in the early 1970s $[54,58,59]$. Following the efficacy observed in lymphoid leukemias and the ability of cladribine to selectively target lymphocyte populations, the drug was considered for potential use in MS [53].

\subsection{Mechanism of Action}

Cladribine (2-CdA) is a small molecule (molecular mass $285.7 \mathrm{~g} / \mathrm{mol}$ [60]) prodrug that is taken up by cells via nucleoside transporter proteins and becomes active in certain cells upon phosphorylation to 2-chlorodeoxyadenosine triphosphate (2-Cd-ATP). 2-CdA undergoes sequential intracellular phosphorylation, first to 2-chlorodeoxyadenosine monophosphate (2-Cd-AMP) mediated by deoxycytidine kinase (DCK), and subsequently to 2-chlorodeoxyadenosine diphosphate (2-Cd-ADP) and 2-Cd-ATP by other kinases. De-phosphorylation by 5'-nucleotidases (5'-NTases) prevents accumulation of 2-Cd-ATP in most cells [31]. Phosphorylation preferentially occurs in $\mathrm{B}$ and $\mathrm{T}$ lymphocytes due to their unique constitutively high DCK and relatively low 5'-NTase levels, compared with other cell types. DCK is a rate-limiting enzyme in the nucleoside salvage pathway that provides deoxyribonucleosides (dNTPs). The high DCK level is thought to be important for lymphocyte clonal expansion during development and immune reactions [61, 62]. Lymphocytes are therefore susceptible to accumulation of 2-Cd-ATP (Fig. 2). In cells where 2-Cd-ATP accumulates, it incorporates into deoxyribonucleic acid (DNA) strands, disrupting DNA synthesis and cell cycle progression, and inhibits enzymes involved in DNA synthesis, leading to cell death in both proliferating and quiescent lymphocytes [31, 59, 63].

While the precise mechanisms by which cladribine exerts its therapeutic effects in patients with MS is not known, its effects on B and T lymphocytes are thought to play a central role. Cladribine preferentially reduces cells of the adaptive immune system, while leaving the innate immune system relatively spared. Absolute lymphocyte counts (ALC) and B- and T-cell subset counts rapidly reach nadir following administration of cladribine tablets, and gradual lymphocyte count recovery begins soon after treatment and continues for months afterwards [64]. In the phase III CLARITY and CLARITY Extension studies [65, 66], median ALC reached nadir, at the lower limit of normal (LLN) at week 13, and was followed by recovery of cell counts back to the normal range (Fig. 3). In year 2, median ALC fell below the LLN but recovered into the normal range by week 84 , or approximately 30 weeks postdose after completion of the second treatment cycle in year 2. Reduction of CD19+ B cells in year 1 also reached nadir at about week 13 (below LLN and approximately $80 \%$ change from baseline), followed by recovery towards baseline values (Fig. 4). CD19+ B-cell counts also fell below LLN in year 2, and recovered to LLN by week 84 . CD4+ T-cell median counts showed a lesser decline from baseline to nadir (approximately 50\% change from baseline, also reached at week 13) in year 1, followed by a more gradual recovery towards baseline (Fig. 5). While CD4 + T cells did not reach the LLN in year 1, they fell below the LLN in year 2 and reached threshold values for recovery by week 96 , approximately 43 weeks post last therapy dose. Median CD8 + T cells never dropped below LLN (Fig. 6) [64]. Analysis of CD4+ T-cell subtypes in ORACLE-MS showed that subpopulations displayed different repopulation dynamics, leading to changes in the 


\section{Clinical Development of Cladribine Tablets}

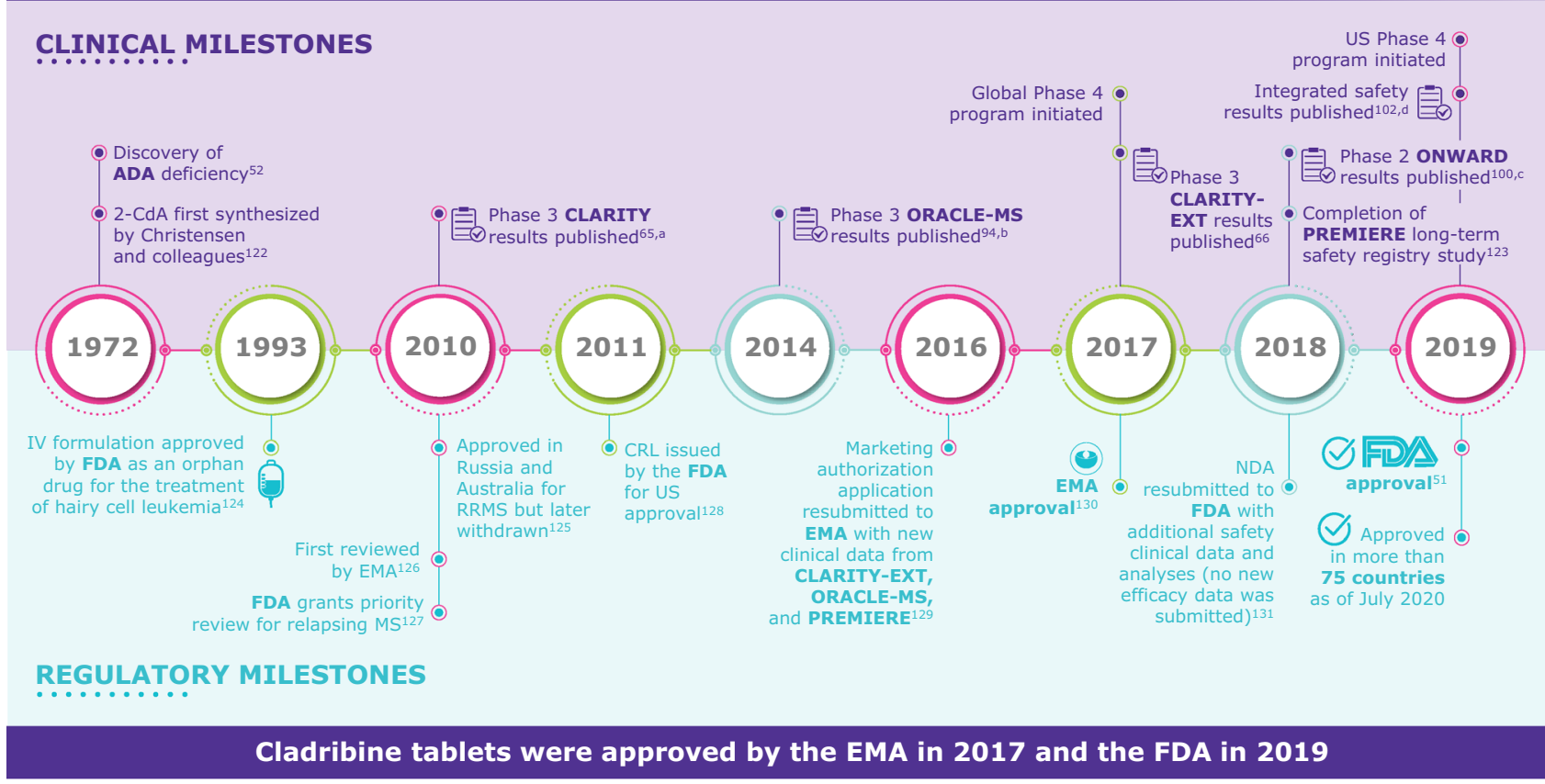

Fig. 1 Cladribine tablets development milestones [51, 52, 65, 66, 94,

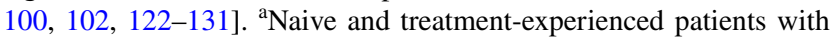
RRMS. ${ }^{\text {b}}$ Treatment-naive patients at high risk for developing MS. ${ }^{\mathrm{c}}$ Patients with active RRMS in combination with IFN- $\beta$. ${ }^{\mathrm{d}}$ Including patients from CLARITY, CLARITY-EXT, ORACLE-MS, and PRE-

relative proportions of the $\mathrm{CD} 4+\mathrm{T}$-cell subpopulations [67]. Median monocyte and neutrophil counts remained within the normal range throughout the CLARITY and CLARITY Extension studies (Figs. 7, 8), while the effects on natural killer (NK) cells were moderate and transient, with a 30-44\% median decrease in NK cells followed by a recovery towards pretreatment levels by week 24 (Fig. 9). These findings support the view that the impact of cladribine on the innate immune system is relatively minor [67]. The preferential reduction of lymphocyte subpopulations, followed by the pattern of lymphocyte count recovery (termed immune reconstitution), may 'reset' the immune system to a less autoreactive state [64], a putative mechanism with considerable potential in the long-term treatment of MS [48].

\subsection{Approvals}

Cladribine tablets were developed as a potential treatment for MS in response to the efficacy seen in early studies of parenteral cladribine and the need for additional treatment options [53, 68, 69]. The pivotal CLARITY trial was completed in 2009 and published in 2010; however, some regulatory authorities indicated in 2011 that improved understanding of safety risks and the overall benefit-risk profile
MIERE. $A D A$ adenosine deaminase, 2-CdA 2-chlorodeoxyadenosine deaminase, $C R L$ complete response letter, EMA European Medicines Agency, FDA Food and Drug Administration, IFN interferon, IV intravenous, $M S$ multiple sclerosis, $N D A$ new drug application, $R R M S$ relapsing-remitting MS

was required. Phase II and III studies that were ongoing at the time were completed, and a long-term safety registry was continued. The additional data served to support the thorough characterization of the safety profile of cladribine tablets in MS. Evaluation of these additional data and analyses of the compound's longer-term benefit-risk profile supported new submissions to regulatory authorities. Cladribine tablets received EMA approval in August 2017 [50] and FDA approval in March 2019 [26]. As of July 2020, cladribine tablets have gained marketing authorization in more than 75 countries for the treatment of patients with various forms of RMS.

\subsection{Dosing Schedule}

Two dosages were investigated during the clinical development of cladribine tablets: $3.5 \mathrm{mg} / \mathrm{kg}$ and $5.25 \mathrm{mg} / \mathrm{kg}$ (cumulative doses over 2 years). In addition, in certain study arms, patients received retreatment in years 3 and 4 (cumulative doses over 4 years of $7.0 \mathrm{mg} / \mathrm{kg}$ and $8.75 \mathrm{mg} / \mathrm{kg}$ ). The $3.5 \mathrm{mg} /$ $\mathrm{kg}$ and $5.25 \mathrm{mg} / \mathrm{kg}$ doses appeared to be equally efficacious, but the $5.25 \mathrm{mg} / \mathrm{kg}$ dose was associated with an increased rate of higher-grade lymphopenia [65]. The $3.5 \mathrm{mg} / \mathrm{kg}$ dose was considered to have the most favorable benefit-risk profile. 

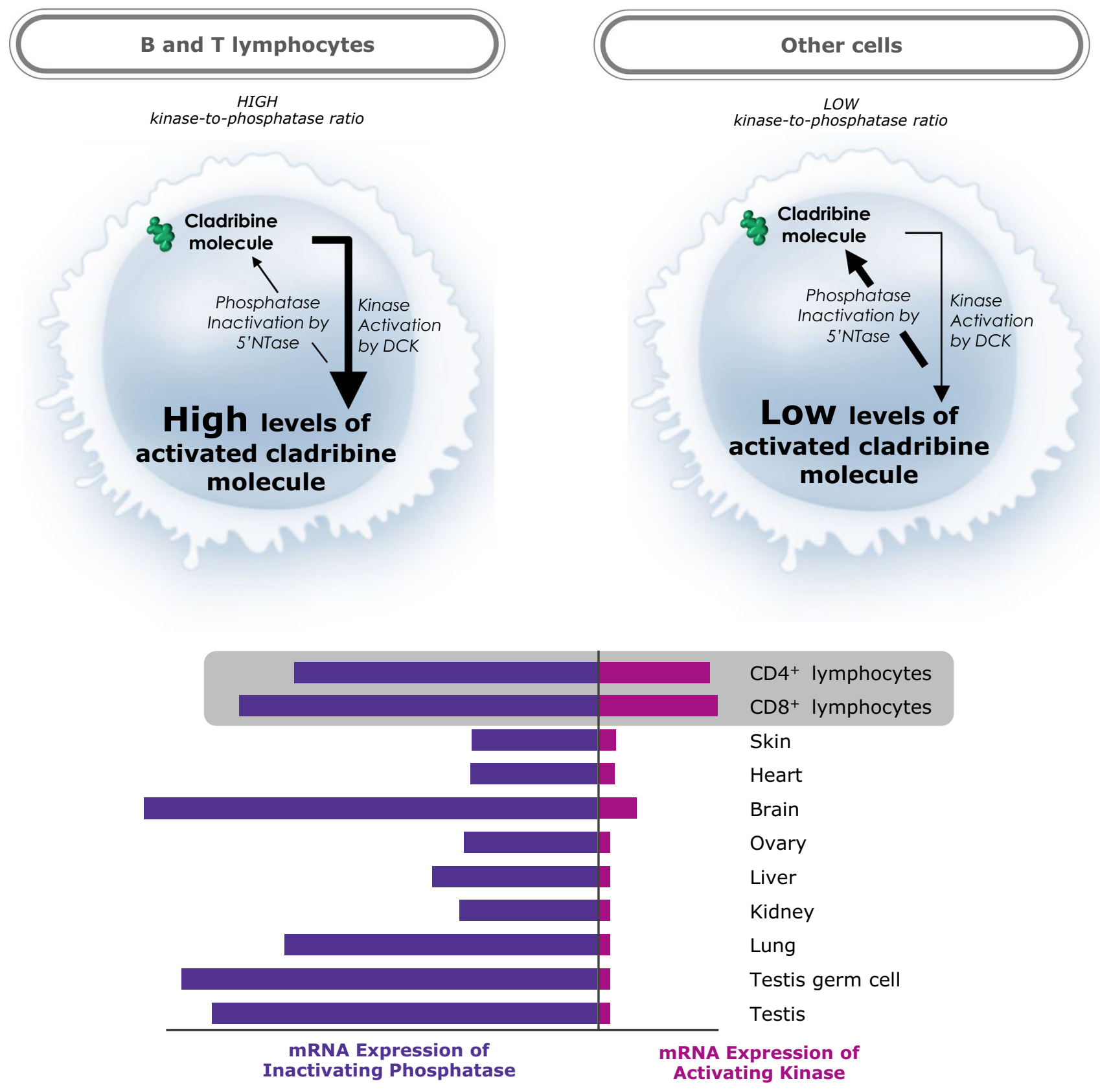

Fig. 2 Ratios of DCK to $5^{\prime}$-NTase mRNA expression in T cells and various non-hematologic cells [58]. 5'-NTase 5'-nucleotidases, $D C K$ deoxycytidine kinase, $m R N A$ messenger RNA. *Calculated

In countries where approved, the recommended cumulative dose of cladribine tablets is $3.5 \mathrm{mg} / \mathrm{kg}$ given over 2 years (one treatment course is $1.75 \mathrm{mg} / \mathrm{kg} /$ year) $[12,26]$. Each course consists of two treatment weeks or cycles-one cycle at the beginning of the first month and one cycle at the beginning of the second month. Each treatment cycle lasts 4 or 5 consecutive days, depending on the patient's weight, and patients receive one or two $10 \mathrm{mg}$ tablets per using data from the BioGPS website (available at https://biogp s.org/\#goto=welcome). Adapted with permission from Giovannoni [58]

day. Lymphocytes must be within normal limits prior to initiating the first course and at least 800 cells $/ \mathrm{mm}^{3}$ prior to initiating the second course. Modeling simulations suggest that $92 \%$ of patients would not require a delay in receiving the second treatment course and $<1 \%$ would be ineligible for treatment in year 2 due to a delay in recovery of more than 6 months [70]. No further treatment with cladribine tablets may be required in years 3 and 4 ; a patient cohort 
Fig. 3 Adaptive immune cell counts in patients with RMS receiving cladribine $3.5 \mathrm{mg} / \mathrm{kg}$ or placebo-absolute lymphocyte counts [58]. $L L N$ lower limit of normal, $Q 1-Q 3$ interquartile range, $R M S$ relapsing multiple sclerosis. Pooled data from CLARITY, CLARITY EXT, and PREMIERE. Visits with a sample size $\geq 30$ are displayed. Adapted with permission from Giovannoni [58]
Fig. 4 Adaptive immune cell counts in patients with RMS receiving cladribine $3.5 \mathrm{mg} /$ $\mathrm{kg}$ or placebo-B (CD19+) cells [64]. $L L N$ lower limit of normal, $Q 1-Q 3$ interquartile range, $R M S$ relapsing multiple sclerosis. Pooled data from CLARITY, CLARITY EXT, and PREMIERE. Visits with a sample size $\geq 30$ are displayed. Adapted with permission from Comi et al. [64]

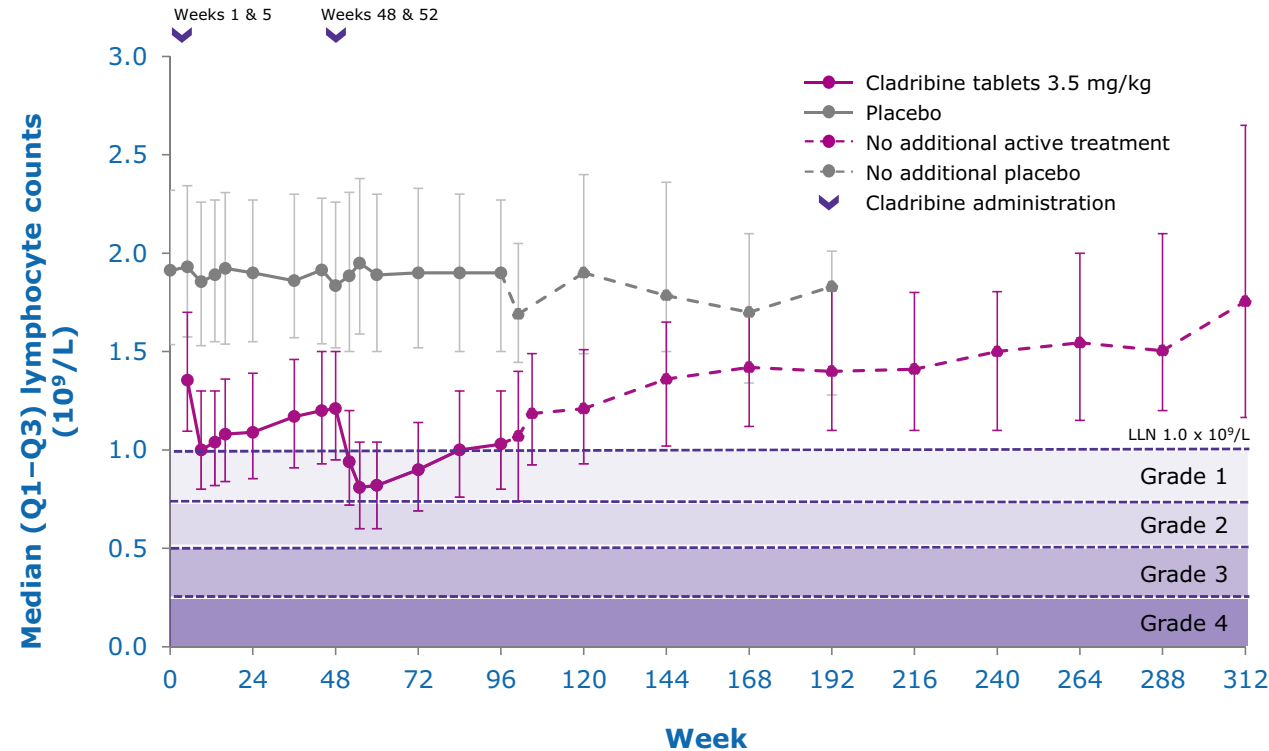

Number of patients

$\begin{array}{lllllllll}-434 & 415 & 263 & 378 & 358 & 86 & 94 & 69 & 34\end{array}$

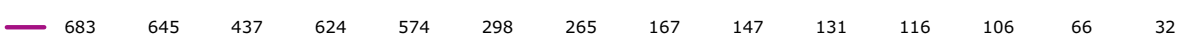

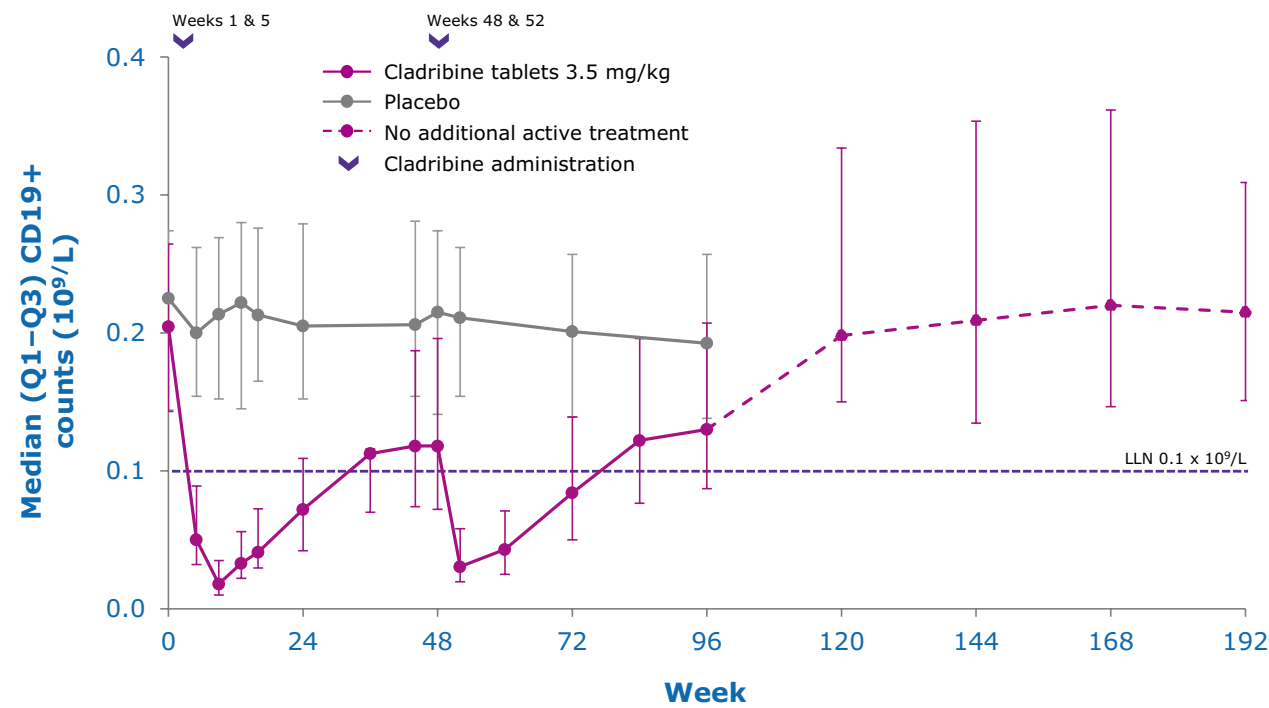

Number of patients

$\begin{array}{ccccc}-79 & 81 & 61 & 74 & 78 \\ -\quad 220 & 203 & 137 & 191 & 195\end{array}$

\subsection{Clinical Pharmacology}

comparable clinical efficacy compared with a study cohort that received placebo in years 3 and 4 [66]. The safety and efficacy of additional treatment courses after year 4 have not been studied. There are no current definitions of treatment failure with cladribine tablets. Any definition would need to be on a case-by-case basis, most likely taking into account disease activity prior to commencing cladribine tablets [71].
Following oral administration, cladribine is rapidly absorbed, reaching maximal plasma concentrations after approximately $0.5 \mathrm{~h}$ (in the fasted state). Food delays absorption but does not affect overall exposure [72]. Oral bioavailability is approximately $40 \%$ compared with parenteral administration; reduced bioavailability is likely due to gastrointestinal efflux mediated by the breast cancer resistance 
Fig. 5 Adaptive immune cell counts in patients with RMS receiving cladribine $3.5 \mathrm{mg} / \mathrm{kg}$ or placebo- $\mathrm{T}$ helper (CD4+) cells [64]. $L L N$ lower limit of normal, $Q 1-Q 3$ interquartile range, $R M S$ relapsing multiple sclerosis. Pooled data from CLARITY, CLARITY EXT, and PREMIERE. Visits with a sample size $\geq 30$ are displayed. Adapted with permission from Comi et al. [64]
Fig. 6 Adaptive immune cell counts in patients with RMS receiving cladribine $3.5 \mathrm{mg} /$ $\mathrm{kg}$ or placebo- $\mathrm{T}$ cytotoxic (CD8+) cells [64]. $L L N$ lower limit of normal, $Q 1-Q 3$ interquartile range, $R M S$ relapsing multiple sclerosis. Pooled data from CLARITY, CLARITY EXT, and PREMIERE. Visits with a sample size $\geq 30$ are displayed. Adapted with permission from Comi et al. [64]
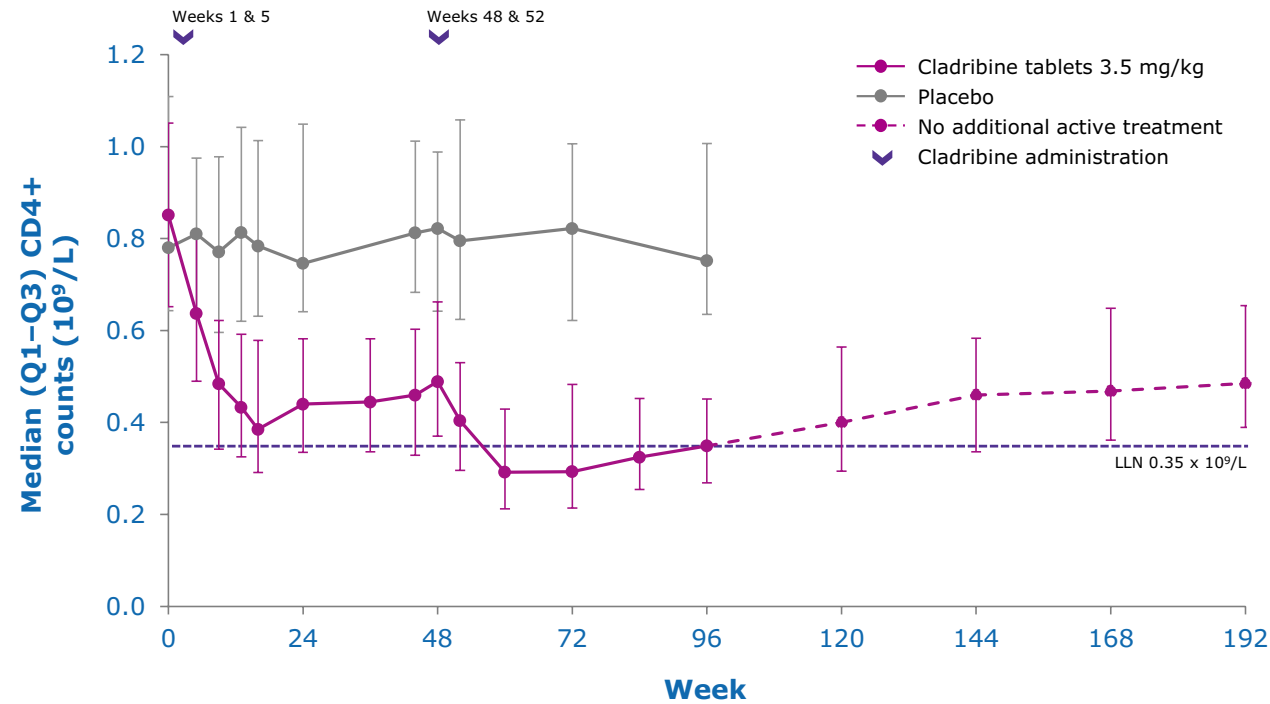

Number of patients

- 79 $81 \quad 61$ $61 \quad 74$

78

38

56

68

64
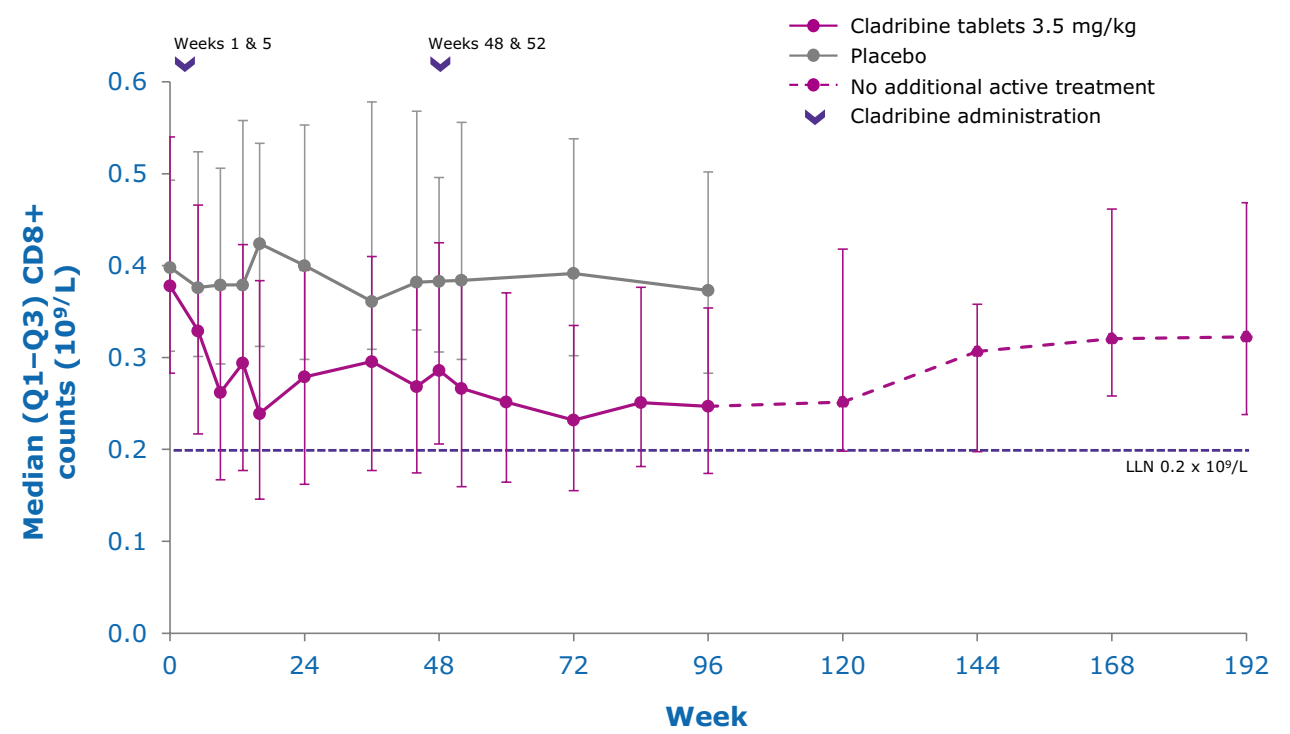

Number of patients

$\begin{array}{ccc}79 & 81 & 61 \\ -\quad 220 & 203 & 137\end{array}$

protein (BCRP), a transporter with affinity for cladribine [72]. Cladribine is rapidly taken up by lymphocytes, where it or its phosphorylated products accumulate, and reach intracellular concentrations that are approximately 30- to 40-fold greater than in plasma within $1 \mathrm{~h}$ of administration [72]. No measurable accumulation of cladribine in plasma has been observed following repeated once-daily oral dosing [72]. The estimated terminal half-life is approximately 1 day [26]. About $50 \%$ of cladribine is cleared renally. Non-renal clearance occurs largely in lymphocytes; accumulated 2-CdAMP and 2-Cd-ATP are cleared via lymphocyte elimination pathways and their intracellular half-life is approximately $10-15 \mathrm{~h}$ [72].

Due to the risk of additive effects on the immune system, concomitant immunosuppressive or myelosuppressive therapy (e.g. cyclosporine, methotrexate) with cladribine is contraindicated. Previous immunomodulatory or immunosuppressive therapy use, including washout periods, should be considered when initiating cladribine tablets $[12,26]$. Cladribine pharmacokinetics was not altered when used concomitantly with the proton pump inhibitor pantoprazole or with IFN- $\beta$. However, the risk of lymphopenia may 
Fig. 7 Innate immune cell counts in patients with RMS receiving cladribine $3.5 \mathrm{mg} / \mathrm{kg}$ or placebo-monocytes [132]. $L L N$ lower limit of normal, $Q 1-Q 3$ interquartile range, $R M S$ relapsing multiple sclerosis. Pooled data from CLARITY, CLARITY EXT, and PREMIERE. Visits with a sample size $\geq 30$ are displayed
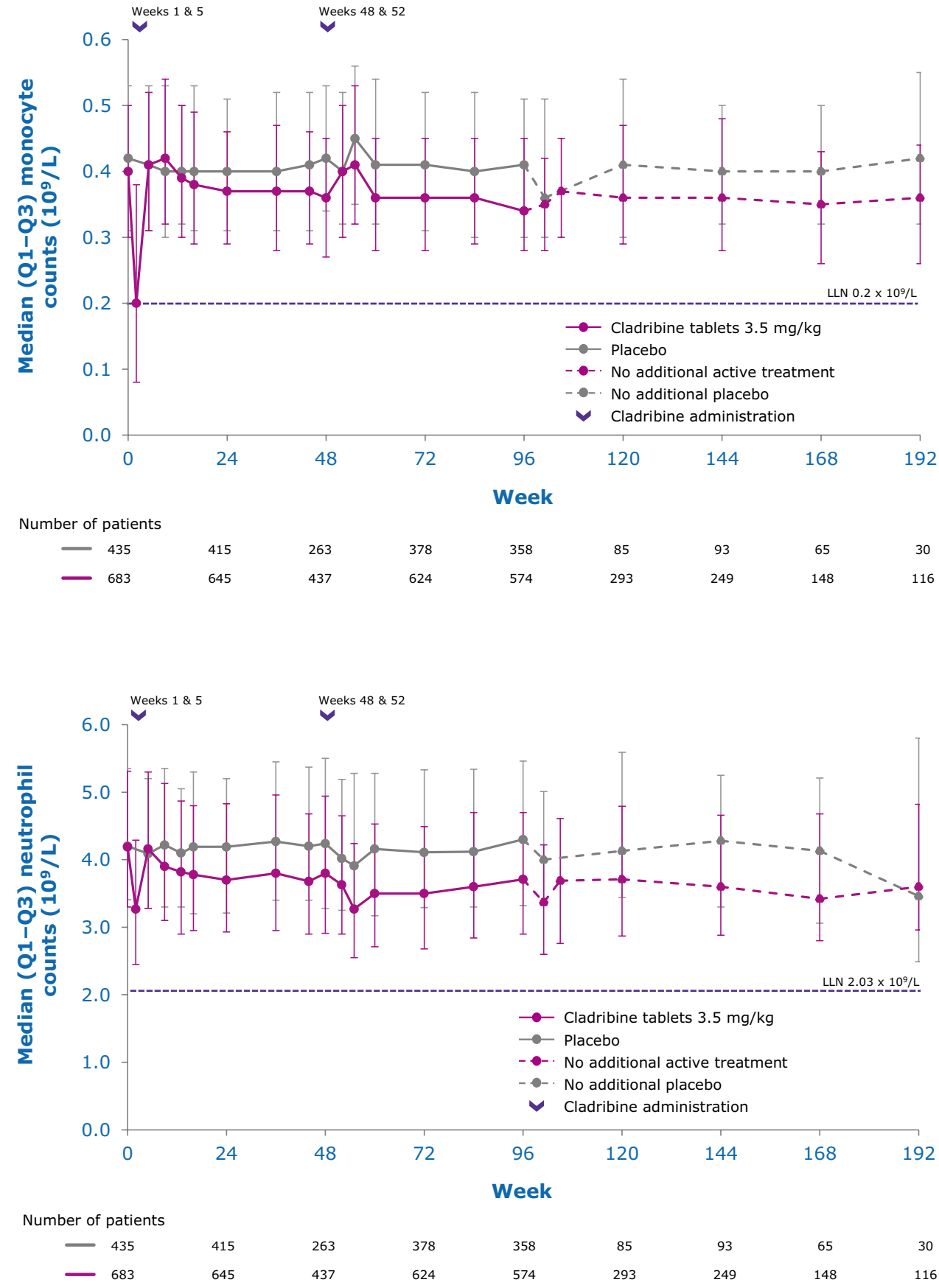

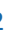

mber of patients
-435
645
437

293
Fig. 8 Innate immune cell counts in patients with RMS receiving cladribine $3.5 \mathrm{mg} / \mathrm{kg}$ or placebo-neutrophils [132]. $L L N$ lower limit of normal, $Q 1-Q 3$ interquartile range, $R M S$ relapsing multiple sclerosis. Pooled data from CLARITY, CLARITY EXT, and PREMIERE. Visits with a sample size $\geq 30$ are displayed increase with concomitant use of IFN- $\beta$. Cladribine may also result in hematological adverse events (AEs) when administered with hematotoxic drugs (e.g. carbamazepine). As a substrate of BCRP, equilibrative nucleoside transporter 1 (ENT1) and concentrative nucleoside transporter 3 (CNT3), coadministration with cladribine may interfere with cladribine exposure. A decrease in cladribine exposure is possible when coadministered with potent inducers of BCRP (e.g. corticosteroids) or P-glycoprotein (e.g. rifampicin); however, acute short-term corticosteroid therapy can be concomitantly administered. Antivirals/antiretrovirals that require intracellular phosphorylation to become active (e.g. lamivudine, ribavirin) could potentially compete with cladribine over phosphorylation, affecting both cladribine and competing compound activity. The hydroxypropyl betadex component in cladribine may interact with active ingredients of other drugs to increase bioavailability, therefore a gap of at least $3 \mathrm{~h}$ between administrations is recommended. Cladribine is 
Fig. 9 Innate immune cell counts in patients with RMS receiving cladribine $3.5 \mathrm{mg} /$ $\mathrm{kg}$ or placebo-natural killer (CD16+/CD56+) cells [67] $L L N$ lower limit of normal, $Q 1-Q 3$ interquartile range, $R M S$ relapsing multiple sclerosis. Visits with a sample size $\geq 30$ are displayed. *Patients who received placebo in CLARITY and cladribine tablets $3.5 \mathrm{mg} /$ $\mathrm{kg}$ in CLARITY EXT. Adapted from Stuve et al. [67] under a Creative Commons CC-BY-NC license

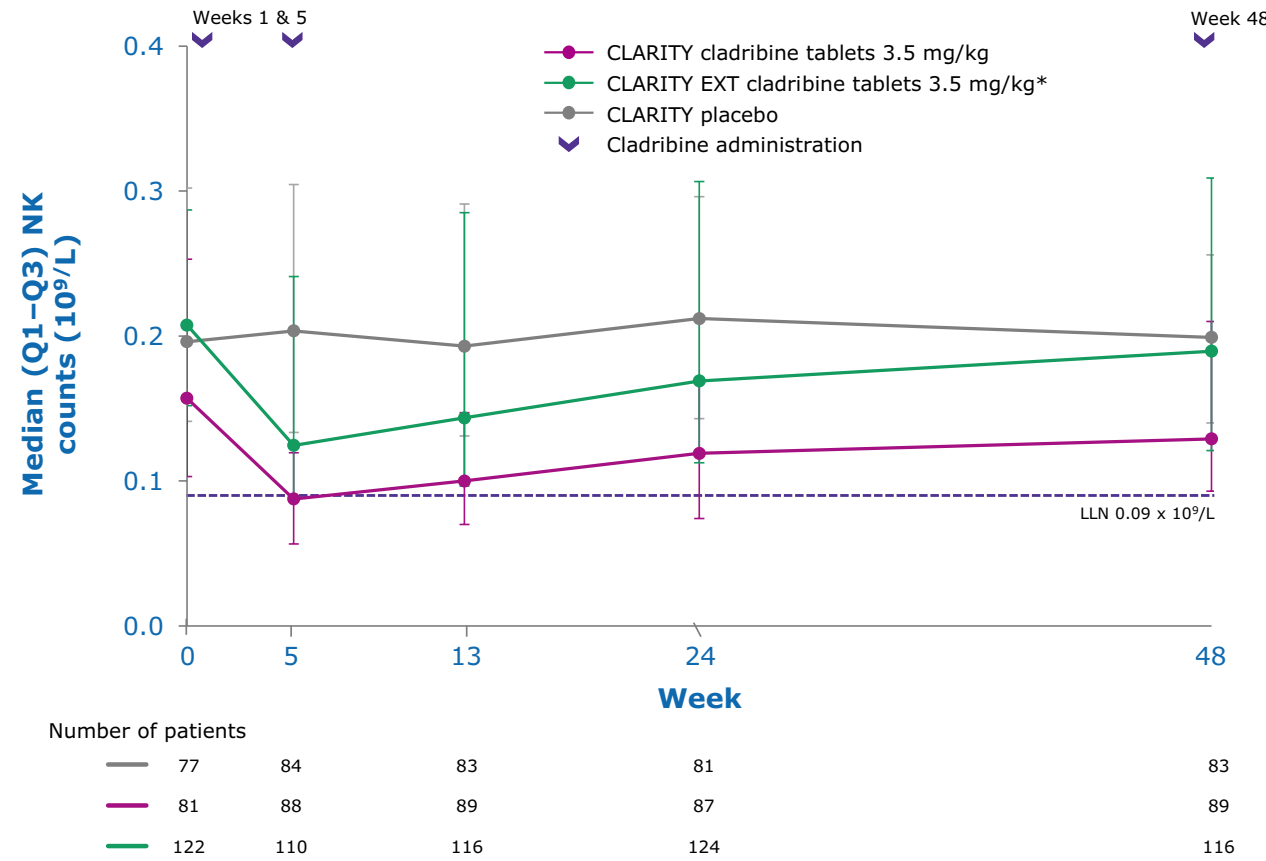

not a substrate of the cytochrome P450 (CYP) pathway and has no known inductive effect on CYP1A2, CYP2B6, and CYP3A4 enzymes [12, 26].

It is not known whether cladribine can reduce the effectiveness of hormonal contraceptives; however, a clinical trial to examine this is ongoing (ClinicalTrials.gov identifier: NCT03745144). A barrier method is currently recommended during treatment with cladribine tablets and for at least 4 weeks after the last dose in each treatment course [26]. In humans, cladribine has a half-life of $<24 \mathrm{~h}$ and is rapidly eliminated [73]. However, in supratherapeutic doses, teratogenicity has been observed in mice and rabbits, and short-term effects have been observed in male mice germ cells [74]. Cladribine tablets should therefore not be administered to pregnant women; pregnancy should be prevented using effective contraception during treatment and 6 months after the last dose in each treatment course in women and men of reproductive potential [26].

As a small molecule, cladribine has been demonstrated to cross the blood-brain barrier (BBB) in animal [75] and human studies [76, 77]. In a study of parenteral cladribine in children with acute myeloid leukemia, cerebrospinal fluid (CSF) concentrations reached approximately $25 \%$ of those in plasma [76]. CNS penetration of cladribine may allow for a treatment effect on lymphocytes that have migrated into the CNS, possibly also affecting lymphoid follicles in the meninges of patients and reducing intrathecal immunoglobulin G (IgG) synthesis. In a study of 29 patients with RRMS who had received parenteral cladribine, 55\% of patients tested negative for oligoclonal bands (OCBs) in CSF post-treatment, despite all patients testing positive for OCB and demonstrating raised Ig concentrations in CSF at baseline [78]. Furthermore, in a 10-year follow-up, Expanded Disability Status Scale (EDSS) progression was significantly delayed in the OCB-negative patients despite both cohorts demonstrating equal characteristics at baseline.

\section{Clinical Studies in Relapsing Forms of MS (RMS): Efficacy}

\subsection{CLARITY (CLAdRIbine Tablets Treating MS orallY): NCT00213135}

CLARITY was a 96-week, phase III, double-blind, randomized, placebo-controlled, parallel-group, multicenter study that evaluated the safety and efficacy of cladribine tablets $3.5 \mathrm{mg} / \mathrm{kg}$ and $5.25 \mathrm{mg} / \mathrm{kg}$ (cumulative dose) in patients with RRMS (Table 1) [65]. Patients with RRMS (according to the McDonald 2001 criteria [79]) at the 2005 trial initiation date were eligible if they had lesions on magnetic resonance imaging (MRI) consistent with MS (according to the criteria of Fazekas et al. [80]), had at least one relapse within 12 months before study entry, and had an EDSS score of no more than 5.5 (on a $0-10$ scale, with higher scores indicating a greater degree of disability). The primary endpoint of the study was annualized relapse rate (ARR) at 96 weeks. Key secondary endpoints included the proportion of patients who were relapse-free and time to 3-month confirmed disability progression (CDP). CDP was defined as the time to a sustained increase, confirmed at 3 months, of at least 1 
EDSS point, or an increase of $\geq 1.5$ if the EDSS score at baseline was 0 . Other assessments included time to first relapse, proportion of patients receiving rescue therapy with IFN- $\beta$, mean number of lesions at 96 weeks for gadoliniumenhancing $(\mathrm{Gd}+)$ T1-weighted lesions, active T2-weighted lesions, and combined unique active (CUA) lesions, defined as new Gd+ T1-weighted lesions or new non-enhancing or enlarging T2-weighted lesions [65].

Among the 1326 patients in the intent-to-treat (ITT) population, 1184 patients $(89.3 \%$ ) completed the 96 -week study $(91.9 \%$ in the cladribine tablets $3.5 \mathrm{mg} / \mathrm{kg}$ group and $87.0 \%$ in the placebo group), and 1165 completed treatment courses. Baseline patient demographics and disease characteristics were generally well-balanced across treatment groups, although patients receiving cladribine tablets $3.5 \mathrm{mg} / \mathrm{kg}$ had a shorter mean duration of disease (7.9, 9.3, and 8.9 mean years for cladribine tablets $3.5 \mathrm{mg} / \mathrm{kg}$ and $5.25 \mathrm{mg} / \mathrm{kg}$, and placebo, respectively; $p=0.005$ for the overall comparison among the three groups). Mean (range) age in the cladribine tablets $3.5 \mathrm{mg} / \mathrm{kg}$ and placebo groups was 37.9 years (18-65) and 38.7 years (18-64), respectively. The percentage of patients who had received a prior DMD was $26.1 \%(n=113)$ in the cladribine tablets $3.5 \mathrm{mg} /$ $\mathrm{kg}$ group and $32.5 \%(n=142)$ in the placebo group. Mean (standard deviation [SD]) EDSS score at baseline was similar among groups (2.8 [1.2] for the cladribine tablets $3.5 \mathrm{mg}$ / $\mathrm{kg}$ group and 2.9 [1.3] for the placebo group) [65].

Treatment with cladribine tablets $3.5 \mathrm{mg} / \mathrm{kg}$ significantly reduced disease activity versus placebo (Fig. 10; Table 2). ARR was 0.14 versus 0.33 , respectively $(p<0.001$ for a relative reduction of 57.6\%) (Fig. 10). The proportion of patients who remained relapse-free at week 96 was significantly higher in the cladribine tablets $3.5 \mathrm{mg} / \mathrm{kg}$ group compared with the placebo group $(80 \%$ vs. $61 \%[p<0.001]$ with imputation of missing values for patients who withdrew early [65]; $81 \%$ vs. $63 \%$ [nominal $p<0.05$ ] without imputation [26]). Additionally, time to first relapse was significantly longer in the cladribine tablets $3.5 \mathrm{mg} / \mathrm{kg}$ group versus placebo [hazard ratio (HR) $0.44,95 \%$ confidence interval (CI) $0.34-0.58 ; p<0.001$ ] [65]. A post-hoc analysis in patients stratified by baseline EDSS severity (with an EDSS of $\geq 3.5$ or $\leq 3.0$ ) at baseline revealed similar benefits in clinical outcomes compared with placebo across subgroups, with a $57.1 \%$ reduction in ARR relative to placebo in the EDSS $\geq 3.5$ subgroup, and a $56.3 \%$ reduction in the EDSS $\leq 3.0$ subgroup ( $p<0.001$ for both groups) [81]. An EDSS of $>3.5$ has been used as a proxy for secondary progressive MS (SPMS) [82-84], as there are no definitive accepted measures indicating when a patient switches from RRMS to SPMS [85].

Cladribine tablets $3.5 \mathrm{mg} / \mathrm{kg}$ significantly reduced the risk of 3-month CDP at 2 years, with a $33 \%$ reduction versus placebo (HR $0.67,95 \%$ CI $0.48-0.93 ; p=0.02$ ) in the primary analysis, which imputed patients who used rescue therapy with SC IFN- $\beta-1 \mathrm{a}$ (11 [2.5\%] and 27 [6.2\%] patients in the $3.5 \mathrm{mg} / \mathrm{kg}$ and placebo groups, respectively) from the time that rescue therapy was started [65]. A post-hoc analysis including all patients (regardless of rescue therapy use) confirmed a significant reduction in the risk of 3-month CDP with cladribine tablets $3.5 \mathrm{mg} / \mathrm{kg}$ versus placebo (41\% risk reduction; HR $0.59,95 \%$ CI $0.43-0.82 ; p=0.0013$ ) [86]. In this analysis, the risk of 6-month CDP was reduced by $47 \%$ with cladribine tablets $3.5 \mathrm{mg} / \mathrm{kg}$ compared with placebo (HR 0.53, 95\% CI 0.36-0.79; $p=0.0016$ ) [86]. ${ }^{1}$ Among patients treated with cladribine tablets $3.5 \mathrm{mg} / \mathrm{kg}, 86 \%$ were free from 3-month CDP at 2 years, versus $79 \%$ with placebo (odds ratio [OR] 1.55, 95\% CI 1.09-2.22, $p=0.02$, in the primary analysis with imputation for patients with incomplete follow-up [65]; 87\% vs. 81\% without imputation [26]). A post-hoc analysis that removed patients with incomplete follow-up also found $86 \%$ of patients treated with cladribine tablets $3.5 \mathrm{mg} / \mathrm{kg}$ versus $79 \%$ with placebo were free from 3-month CDP at 2 years (OR 1.62, 95\% CI 1.12-2.35; $p=0.0105$ ), and $91 \%$ of patients treated with cladribine tablets $3.5 \mathrm{mg} / \mathrm{kg}$ versus $85 \%$ with placebo were free from 6-month CDP at 2 years (OR 1.87, 95\% CI 1.19-2.94; $p=0.0064$ ) [87]. A post-hoc analysis in a subgroup of 261 patients with high disease activity (HDA), or rapidly evolving severe RRMS, defined as two or more relapses in the year prior to study entry, found that this group had greater reduction in both 3-month CDP (72\% risk reduction, HR $0.28,95 \%$ CI $0.15-0.54 ; p=0.0061)$ and 6-month CDP (82\% risk reduction; HR $0.18,95 \% \mathrm{CI} 0.08-0.44 ; p=0.0036$ ) than the overall study population [88].

Assessment of active brain lesions on MRI showed that patients treated with cladribine tablets $3.5 \mathrm{mg} / \mathrm{kg}$ had a reduction of $85.7 \%$ in the mean number of $\mathrm{T} 1 \mathrm{Gd}+$ lesions versus placebo ( 0.12 vs. $0.91 ; p<0.001)$ at 2 years (Table 2$)$, with consistent reductions seen in the first and second treatment years [89]. At 2 years, $87.2 \%$ of patients treated with cladribine tablets $3.5 \mathrm{mg} / \mathrm{kg}$ were free of new $\mathrm{T} 1 \mathrm{Gd}+$ lesions, compared with $47.4 \%$ of patients receiving placebo (OR 8.14, 95\% CI 5.73-11.57; $p<0.0001$ ) [87]. Patients treated with cladribine tablets $3.5 \mathrm{mg} / \mathrm{kg}$ also showed a $73.4 \%$ reduction in the mean number of active $\mathrm{T} 2$-weighted lesions versus placebo at 2 years $(0.38$ vs. $1.43 ; p<0.001)$ [89], and $61.8 \%$ of patients treated with cladribine tablets $3.5 \mathrm{mg} / \mathrm{kg}$ were free of active T2 lesions versus $27.6 \%$ treated with placebo at 2 years (OR 5.34, 95\% CI 3.60-7.91; $p<0.0001$ ) [87]. Cladribine tablets $3.5 \mathrm{mg} / \mathrm{kg}$ also reduced

\footnotetext{
1 The 47\% reduction is based on a Cox proportional hazards model with EDSS at baseline as the fixed effect. Other analyses utilize a Cox regression that adjusts for treatment group and geographic region, and result in a $46 \%$ reduction in risk of 6-month CDP.
} 


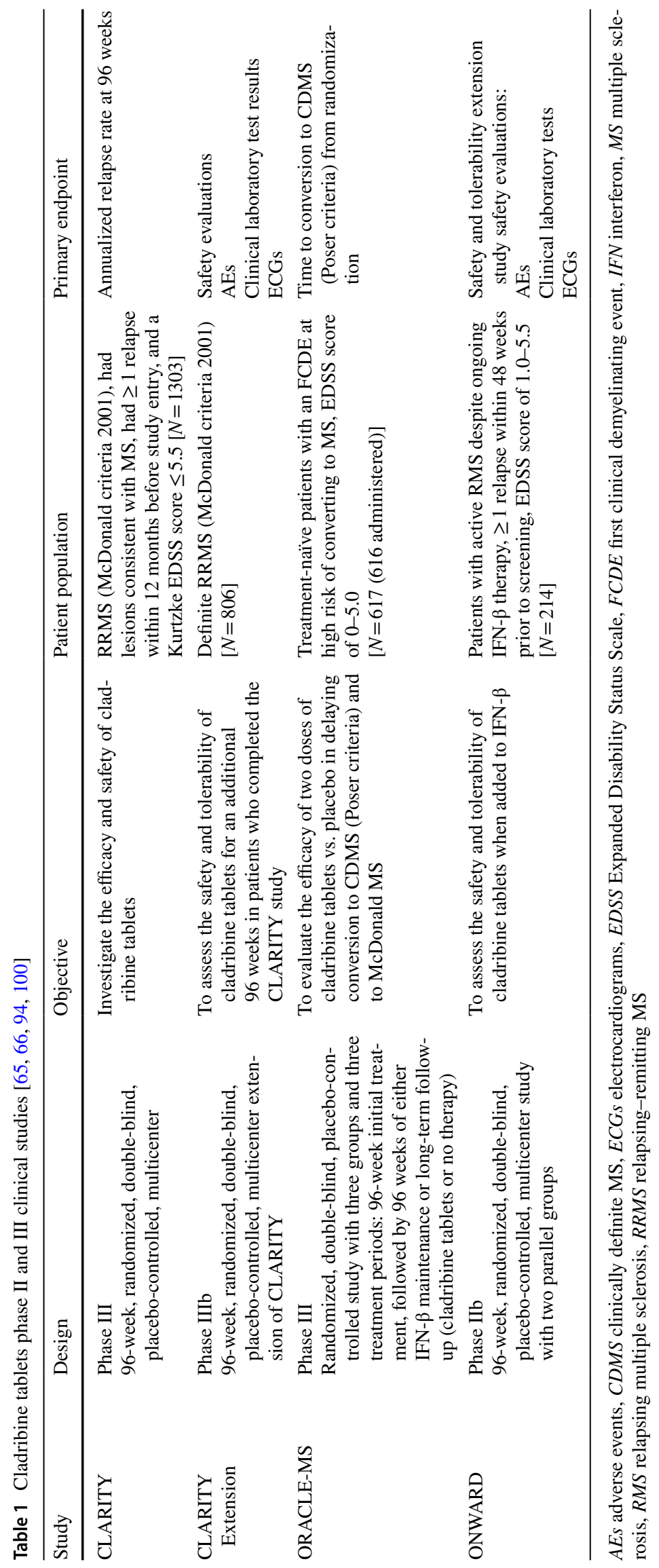




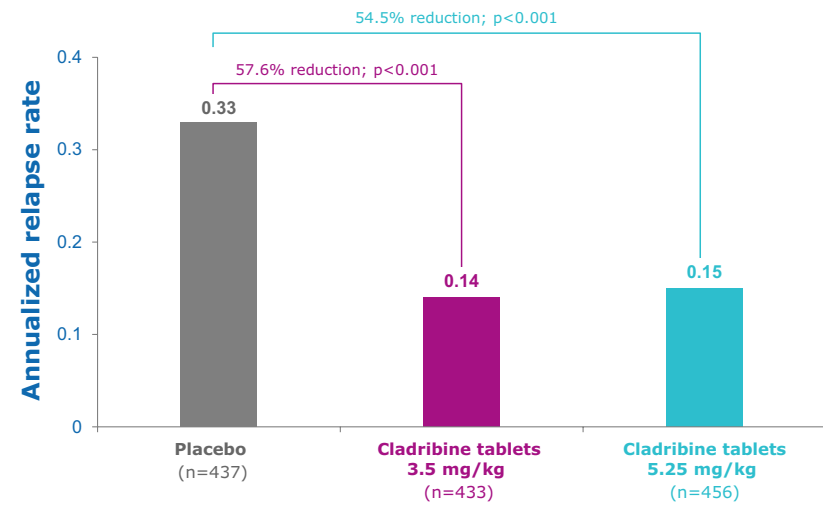

Fig. 10 CLARITY: annualized qualified relapse rate [65]. EDSS Expanded Disability Status Scale. Qualified relapses were defined as a $\geq 2$-point increase in at least one functional system, or $\geq 1$ point increase in at least two functional systems of the EDSS, excluding bladder/bowel or cognition changes, lasting $\geq 24 \mathrm{~h}$, in the absence of fever, and preceded by $\geq 30$ days of clinical stability or improvement. Adapted with permission from Giovannoni et al. [65]

the mean number of CUA lesions (per patient per scan) by $74.4 \%$ versus placebo at 2 years $(0.43$ vs. $1.72 ; p<0.001)$ [65]. Among the patients treated with cladribine tablets $3.5 \mathrm{mg} / \mathrm{kg}, 60 \%$ were MRI lesion activity-free (defined as having no new $\mathrm{T} 1 \mathrm{Gd}+$ lesions and no active $\mathrm{T} 2$ lesions on cranial MRI) at 2 years versus $25.5 \%$ receiving placebo (OR $5.52,95 \%$ CI $3.68-8.27 ; p<0.0001$ ) [87].

In CLARITY, an exploratory analysis showed brain atrophy rates (percentage of brain volume changes [PBVC]) were significantly reduced in patients treated with cladribine tablets $3.5 \mathrm{mg} / \mathrm{kg}$ versus placebo $(0.77 \%$ vs. $0.95 \%$; $p=0.02$ ), based on PBVC over months 6-24, to avoid the confounding influence of pseudoatrophy in the first 6 months [90]. Annualized brain volume changes (mean PBVC/year) were significantly reduced in patients treated with cladribine tablets $3.5 \mathrm{mg} / \mathrm{kg}$ versus placebo $(0.56 \%$ vs. $0.70 \%$; $p=0.01$ ). Brain atrophy rates showed a significant correlation with the cumulative probability of disability progression in the overall study population (HR $0.67,95 \%$ CI $0.57-0.79$; $p<0.001$ ); patients with the lowest brain atrophy rates (PBVC/year greater than $-0.4 \%$ ) showed the highest probability of remaining free from disability progression (89\%) at 2 years [90].

A post-hoc analysis of data from the CLARITY study assessed the proportion of patients with no evidence of disease activity (NEDA), defined as patients having no relapse, no 3-month CDP, and no new MRI lesions (no T1 Gd+ or active T2 lesions) [87]. NEDA was analyzed using observed data (no imputation of missing data) at 6 months $(n=1174)$, 1 year $(n=1140)$, and 2 years $(n=1192)$. At 6 months, 1 year, and 2 years, proportions of patients achieving NEDA were $67 \%, 54 \%$, and $44 \%$, respectively, in the cladribine tablets $3.5 \mathrm{mg} / \mathrm{kg}$ group, compared with $39 \%, 24 \%$, and $16 \%$, respectively, in the placebo group ( $p<0.0001$ for cladribine tablets $3.5 \mathrm{mg} / \mathrm{kg}$ vs. placebo at each time point). Results were similar when analyzed using 6-month CDP for the disability component of NEDA ( $47 \%$ vs. $17 \%$, cladribine tablets $3.5 \mathrm{mg} / \mathrm{kg}$ vs. placebo, at 2 years; OR $4.25,95 \%$ CI 3.03-5.96; $p<0.0001$ ) [87].

NEDA was also evaluated in subgroups of patients with HDA at baseline. Subgroups of interest included patients with high relapse activity (two or more relapses in the year prior to study entry), and an expanded group including those with high relapse activity (regardless of treatment status) plus patients with persistent disease activity despite treatment with a DMD (one or more relapses in the year prior to study entry while taking a DMD, and one or more T1 $\mathrm{Gd}+$ lesion(s) or nine or more $\mathrm{T} 2$ lesions). In all subgroups evaluated (both HDA subgroups and their counterparts with lower disease activity), the proportions of patients achieving NEDA were significantly higher with cladribine tablets $3.5 \mathrm{mg} / \mathrm{kg}$ compared with placebo, but ORs were greater for HDA than non-HDA subgroups (ORs 7.8-8.0 for HDA subgroups, compared with 3.5-3.6 for the respective non-HDA subgroups), indicating that the greatest treatment benefit, relative to placebo, was attained by patients with HDA [88].

NEDA was further evaluated in subgroups of patients with a baseline EDSS severity of $\geq 3.5$ or $\leq 3.0$. The percentage of patients achieving NEDA using 3 -month CDP at 2 years was $48.6 \%$ versus $17.3 \%$ in the EDSS $\geq 3.5$ subgroup, and $41.8 \%$ versus $14.8 \%$ in the EDSS $\leq 3.0$ subgroup (cladribine tablets $3.5 \mathrm{mg} / \mathrm{kg}$ vs. placebo, respectively). ORs (95\% CI) were similar across subgroups and favored cladribine tablets $3.5 \mathrm{mg} / \mathrm{kg}$ over placebo (4.51 [2.65-7.69] and 4.12 [2.65-6.40], EDSS $\geq 3.5$ and EDSS $\leq 3.0$, respectively; $p<0.0001$ for both groups) [87]. Patients had active disease as a criterion for enrollment into the trials.

\subsection{CLARITY Extension: NCT00641537}

CLARITY Extension was a 96-week, phase IIIb, doubleblind, randomized, parallel-group, multicenter, extension study investigating long-term safety, tolerability, and efficacy of cladribine tablets for an additional 2 years beyond the 2-year CLARITY study (Table 1) [66]. Patients were eligible for the extension study if they completed the 2-year study period in CLARITY and had normal lymphocyte counts and other normal hematologic results within 28 days of the first planned additional dose [66]. Eligible patients who received placebo in CLARITY were assigned to cladribine tablets $3.5 \mathrm{mg} / \mathrm{kg}$, and patients treated with cladribine tablets in CLARITY were re-randomized (2:1) to an additional 2-year course of cladribine tablets $3.5 \mathrm{mg} / \mathrm{kg}$ or placebo (Fig. 11). Clinical endpoints were considered exploratory, and included ARR, proportion of patients free from relapses, time to first relapse, and time to CDP [66]. MRI 
Table 2 CLARITY efficacy: clinical and imaging endpoints and relapses during the 96-week study (ITT population) [65]

\begin{tabular}{|c|c|c|c|}
\hline Endpoint & $\begin{array}{l}\text { Placebo } \\
{[n=437]}\end{array}$ & $\begin{array}{l}\text { Cladribine tablets } 3.5 \mathrm{mg} / \mathrm{kg} \\
{[n=433]}\end{array}$ & $\begin{array}{l}\text { Cladribine tablets } 5.25 \mathrm{mg} / \mathrm{kg} \\
{[n=433]}\end{array}$ \\
\hline \multicolumn{4}{|l|}{ Relapse rate (primary endpoint) } \\
\hline $\operatorname{ARR}(95 \% \mathrm{CI})$ & $0.33(0.29-0.38)$ & $0.14(0.12-0.17)$ & $0.15(0.12-0.17)$ \\
\hline $\begin{array}{l}\text { Relative reduction in ARR for cladribine vs. } \\
\text { placebo, } \%^{\mathrm{a}}\end{array}$ & & 57.6 & 54.5 \\
\hline$p$ value $\mathrm{e}^{\mathrm{b}}$ & & $<0.001$ & $<0.001$ \\
\hline \multicolumn{4}{|l|}{ Relapse-free rate } \\
\hline Patients without relapse $[n(\%)]$ & $266(60.9)$ & $345(79.7)$ & $360(78.9)$ \\
\hline OR for cladribine vs. placebo $(95 \% \mathrm{CI})^{\mathrm{c}}$ & & $2.53(1.87-3.42)$ & $2.43(1.81-3.27)$ \\
\hline$p$ value $^{\mathrm{d}}$ & & $<0.001$ & $<0.001$ \\
\hline \multicolumn{4}{|l|}{ Relapse at 96 weeks } \\
\hline \multicolumn{4}{|l|}{ Number of relapses $[n(\%)]$} \\
\hline 0 & $266(60.9)$ & $345(79.7)$ & $360(78.9)$ \\
\hline 1 & 109 (24.9) & $69(15.9)$ & $77(16.9)$ \\
\hline 2 & $44(10.1)$ & $13(3.0)$ & $13(2.9)$ \\
\hline 3 & $15(3.4)$ & $5(1.2)$ & $5(1.1)$ \\
\hline$\geq 4$ & $3(0.7)$ & $1(0.2)$ & $1(0.2)$ \\
\hline$p$ value $\mathrm{e}^{\mathrm{e}}$ & & $<0.001$ & $<0.001$ \\
\hline \multicolumn{4}{|l|}{ Need for rescue therapy } \\
\hline Patients receiving rescue therapy $[n(\%)]$ & $27(6.2)$ & $11(2.5)$ & $9(2.0)$ \\
\hline OR for cladribine vs. placebo $(95 \% \mathrm{CI})^{\mathrm{c}}$ & & $0.40(0.19-0.81)$ & $0.31(0.14-0.66)$ \\
\hline$p$ value $^{\mathrm{d}}$ & & 0.01 & 0.003 \\
\hline \multicolumn{4}{|l|}{ Time to first relapse } \\
\hline 15th percentile of time to event, months ${ }^{\mathrm{f}}$ & 4.6 & 13.4 & 13.3 \\
\hline HR for cladribine vs. placebo $(95 \% \mathrm{CI})^{\mathrm{g}}$ & & $0.44(0.34-0.58)$ & $0.46(0.36-0.60)$ \\
\hline$p$ value $^{\mathrm{g}}$ & & $<0.001$ & $<0.001$ \\
\hline \multicolumn{4}{|l|}{ Time to 3-month CDP } \\
\hline 10th percentile of time to event, months ${ }^{\mathrm{f}}$ & 10.8 & 13.6 & 13.6 \\
\hline HR for cladribine vs. placebo $(95 \% \mathrm{CI})^{\mathrm{g}}$ & & $0.67(0.48-0.93)$ & $0.69(0.49-0.96)$ \\
\hline$p$ value $^{\mathrm{g}}$ & & 0.02 & 0.03 \\
\hline \multicolumn{4}{|l|}{ Patients without a 3-month CDP } \\
\hline Patients with no change $[n(\%)]$ & $347(79.4)$ & $371(85.7)$ & $387(84.9)$ \\
\hline OR for cladribine vs. placebo $(95 \% \mathrm{CI})^{\mathrm{c}}$ & & $1.55(1.09-2.22)$ & $1.46(1.03-2.07)$ \\
\hline$p$ value $^{\mathrm{d}}$ & & 0.02 & 0.03 \\
\hline \multicolumn{4}{|l|}{ Lesion activity on brain MRI } \\
\hline \multicolumn{4}{|l|}{ Gd + T1-weighted lesions } \\
\hline Mean number & 0.91 & 0.12 & 0.11 \\
\hline Relative reduction, $\%$ & & 85.7 & 87.9 \\
\hline \multicolumn{4}{|l|}{ Active T2-weighted lesions } \\
\hline Mean number & 1.43 & 0.38 & 0.33 \\
\hline Relative reduction, $\%$ & & 73.4 & 76.9 \\
\hline \multicolumn{4}{|l|}{ Combined unique lesions } \\
\hline Mean number & 1.72 & 0.43 & 0.38 \\
\hline Relative reduction, $\%$ & & 74.4 & 77.9 \\
\hline$p$ value $^{\mathrm{h}}$ & & $<0.001$ & $<0.001$ \\
\hline
\end{tabular}

$A R R$ annualized relapse rate, $C D P$ confirmed disability progression, $C I$ confidence interval, $G d+$ gadolinium-enhancing, $H R$ hazard ratio, $I T T$ intent-to-treat, $M R I$ magnetic resonance imaging, $O R$ odds ratio

${ }^{a}$ The relative reduction in the ARR was calculated as the ratio of the difference in the ARR between the placebo group and the cladribine group to the ARR rate in the placebo group

${ }^{\mathrm{b}}$ The $p$ value was based on a Wald Chi-square test from an analysis of the number of relapses with the use of a Poisson regression model with 
Table 2 (continued)

fixed effects for treatment and region and the log of time in the study as an offset variable

${ }^{c}$ ORs and associated $95 \%$ CIs were estimated with the use of a logistic regression model with fixed effects for study group and region

${ }^{\mathrm{d}}$ The $p$ value was based on a Wald Chi-square test from an endpoint analysis with the use of a logistic-regression model with fixed effects for study group and region

${ }^{\mathrm{e}}$ The $p$ value was based on a Cochran-Mantel-Haenszel test with adjustment for the baseline number of relapses

${ }^{\mathrm{f}}$ The 10th and 15th percentile values were estimated from the Kaplan-Meier survival curve

${ }^{\mathrm{g}}$ The HR, 95\% CI, and $p$ values were based on a Cox proportional hazards model with fixed effects for study group and region

${ }^{\mathrm{h}}$ The $p$ value is for all comparisons with placebo for imaging measurements and was based on a non-parametric analysis of covariance model on ranked data with fixed effects for study group and region and number of GD+ T1-weighted lesions at baseline as a covariate

endpoints included number of $\mathrm{T} 1 \mathrm{Gd}+$ lesions, number of active $\mathrm{T} 2$ lesions, total $\mathrm{T} 2$ lesion volume, and proportions of patients with no $\mathrm{T} 1 \mathrm{Gd}+$ lesions or no active $\mathrm{T} 2$ lesions [91]. Patients who received cladribine tablets in CLARITY and CLARITY EXT did so as a result of randomization and not as a result of evidence of disease activity following the CLARITY study, which differs from the clinical design of other phase III extension studies [66, 92]. It could be of further interest to study such patients.

Of the 1184 patients who completed CLARITY, 867 (73.2\%) were enrolled in CLARITY Extension. As the first patients completed the CLARITY study, the CLARITY Extension study was not yet ready to start. Consequently, there was some variability in the interval between completing CLARITY and entering the Extension (median 40.3 weeks, range $0.1-118.0$ weeks) [66]. There were five treatment groups: patients who received cladribine tablets $3.5 \mathrm{mg} / \mathrm{kg}$ in CLARITY followed by placebo in CLARITY Extension (CP3.5), $n=98$; patients who received cladribine tablets $5.25 \mathrm{mg} / \mathrm{kg}$ in CLARITY followed by placebo in CLARITY Extension (CP5.25), $n=92$; patients who received cladribine tablets $3.5 \mathrm{mg} / \mathrm{kg}$ in CLARITY followed by cladribine tablets $3.5 \mathrm{mg} / \mathrm{kg}$ in CLARITY Extension (CC7.0), $n=186$; patients who received cladribine tablets $5.25 \mathrm{mg} / \mathrm{kg}$ in CLARITY followed by cladribine tablets $3.5 \mathrm{mg} / \mathrm{kg}$ in CLARITY Extension (CC8.75), $n=186$; and patients who received placebo in CLARITY followed by cladribine tablets $3.5 \mathrm{mg} / \mathrm{kg}$ in CLARITY Extension (PC3.5), $n=244$ [66]. In CLARITY Extension, 806 patients were treated, of whom 738 (91.6\%) completed the 2-year study. Demographic and disease characteristics at the start of CLARITY Extension were generally similar across groups, except the PC3.5 group (patients who received placebo in CLARITY), which showed evidence of greater disease activity than those who received cladribine tablets in CLARITY [66]. In particular, patients in the PC3.5 group had greater numbers and volume of $\mathrm{T} 1 \mathrm{Gd}+$ lesions versus those who received cladribine tablets $3.5 \mathrm{mg} / \mathrm{kg}$ in CLARITY [66].

Treatment with cladribine tablets $3.5 \mathrm{mg} / \mathrm{kg}$ for 2 years followed by 2 years of treatment with placebo (CP3.5) demonstrated durable clinical benefits at year 4; these efficacy results were similar to those of patients who had 4 years of cladribine tablets $3.5 \mathrm{mg} / \mathrm{kg}$ treatment (CC7.0), with no significant differences observed between CP3.5 and CC7.0 across clinical efficacy endpoints (Table 3) [66]. MRI endpoints at the end of year 4 consistently showed high percentages of patients with no new $\mathrm{T} 1 \mathrm{Gd}+$ lesions in both the $\mathrm{CP} 3.5$ and $\mathrm{CC} 7.0$ groups, although significantly more patients who received additional cladribine (4 years' active treatment) remained free from $\mathrm{T} 1 \mathrm{Gd}+$ lesions $(73.0 \% \mathrm{vs}$. $88.9 \%$, CP3.5 vs. CC7.0, respectively; $p=0.001$ ) [91]. Exploratory post-hoc analysis suggested that NEDA status was durable in patients treated with cladribine tablets $3.5 \mathrm{mg} / \mathrm{kg}$ : overall, $42 \%$ and $48 \%$ of patients in the CP3.5 and CC7.0 groups $(p=0.31)$, respectively, had NEDA during the first year of the CLARITY Extension study [93]. The proportion of patients reaching NEDA status over the longterm with oral cladribine merits further research.

\subsection{ORACLE-MS (ORAI CLadribine for Early MS): NCT00725985}

ORACLE-MS was a 96-week, phase III, double-blind, randomized, placebo-controlled, multicenter study investigating the effect of cladribine tablets on conversion to clinically definite MS (CDMS) in patients with early signs of disease as evidenced by a first clinical demyelinating event (Table 1) [94]. Patients with a first clinical demyelinating event $\leq 75$ days before screening were randomized to cladribine tablets 3.5 or $5.25 \mathrm{mg} / \mathrm{kg}$ (cumulative dose over 2 years) or placebo. The planned number of subjects was 600 (200 per treatment group) and the primary endpoint was time to conversion to CDMS [94].

Of the 617 patients enrolled and randomized, 206 were assigned to cladribine tablets $3.5 \mathrm{mg} / \mathrm{kg}, 205$ were assigned to cladribine tablets $5.25 \mathrm{mg} / \mathrm{kg}$, and 206 were assigned to placebo $(\mathrm{ITT}=616$; one patient in the $5.25 \mathrm{mg} / \mathrm{kg}$ group discontinued after randomization but before receiving study drug). Baseline patient demographics and disease characteristics were well-balanced across treatment groups; mean age across groups was between 31.7 and 32.2 years, and each group was $63-67 \%$ female. At the end of year 2, 363 patients (59\%) had completed all treatments, and 149 patients (24\%) had permanently discontinued treatment. Cladribine tablets 


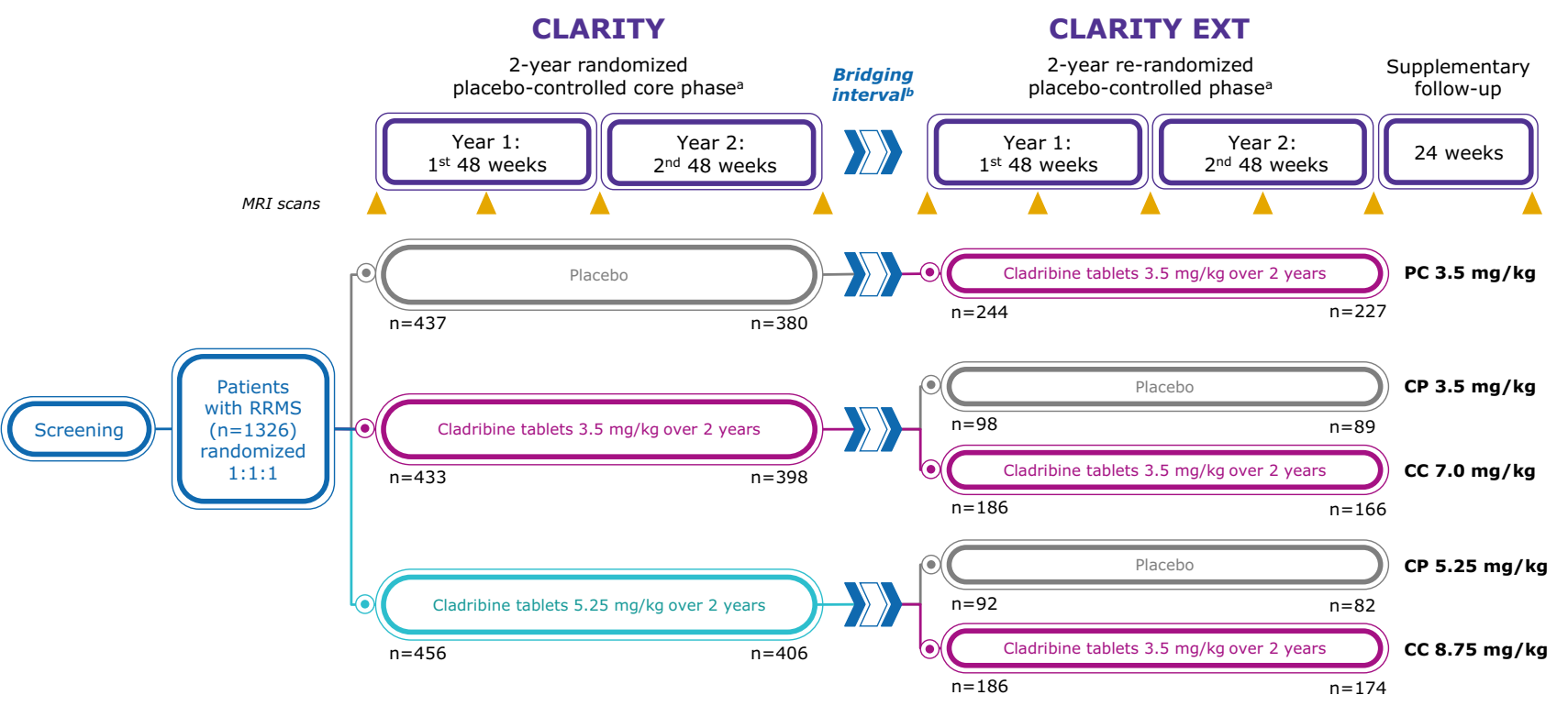

Years 1-2

Years 3-4

Fig. 11 CLARITY Extension: study schema [66]. CP $3.5 \mathrm{mg} / \mathrm{kg}$ cladribine tablets $3.5 \mathrm{mg} / \mathrm{kg}$ in CLARITY followed by placebo in CLARITY Extension, $C P 5.25 \mathrm{mg} / \mathrm{kg}$ cladribine tablets $5.25 \mathrm{mg} / \mathrm{kg}$ in CLARITY followed by placebo in CLARITY Extension, $C C 7 \mathrm{mg} /$ $\mathrm{kg}$ cladribine tablets $3.5 \mathrm{mg} / \mathrm{kg}$ in CLARITY followed by cladribine tablets $3.5 \mathrm{mg} / \mathrm{kg}$ in CLARITY Extension, $C C 8.75 \mathrm{mg} / \mathrm{kg}$ cladribine tablets $5.25 \mathrm{mg} / \mathrm{kg}$ in CLARITY followed by cladribine tablets $3.5 \mathrm{mg} / \mathrm{kg}$ in CLARITY Extension, DMD disease-modifying drug, MRI magnetic resonance imaging, $P C 3.5 \mathrm{mg} / \mathrm{kg}$ placebo in CLARITY followed by cladribine tablets $3.5 \mathrm{mg} / \mathrm{kg}$ in CLARITY Extension, RRMS relapsing-remitting multiple sclerosis. ${ }^{a}$ Each short course of treatment comprised one or two 10-mg cladribine tablets taken once daily for 4 or 5 consecutive days, or an equivalent number of matching placebo tablets. ${ }^{\mathrm{b}}$ As the first patients completed the CLARITY study, the CLARITY EXTENSION study was not yet ready to start. Consequently, after completing CLARITY, there was a variable gap period (bridging interval) before patients entered the Extension (the median gap duration for the overall population was 40.3 weeks). Patients who had received interferon- $\beta$ or glatiramer acetate during the gap period had to discontinue their DMD therapy at least 3 months before the first study day of the Extension [66]. Adapted with permission from Giovannoni et al. [66]

Table 3 CLARITY Extension efficacy [66]

\begin{tabular}{|c|c|c|c|c|}
\hline \multirow[t]{2}{*}{ PC $3.5 \mathrm{mg} / \mathrm{kg}[n=244]$} & \multicolumn{2}{|c|}{ Cladribine tablets $3.5 \mathrm{mg} / \mathrm{kg}$} & \multicolumn{2}{|c|}{ Cladribine tablets $5.25 \mathrm{mg} / \mathrm{kg}$} \\
\hline & $\mathrm{CP} 3.5 \mathrm{mg} / \mathrm{kg}[n=98]$ & $\mathrm{CC} 7.0 \mathrm{mg} / \mathrm{kg}[n=186]$ & CP $5.25 \mathrm{mg} / \mathrm{kg}[n=92]$ & $\begin{array}{l}\mathrm{CC} 8.75 \mathrm{mg} / \mathrm{kg} \\
{[n=186]}\end{array}$ \\
\hline $0.10(0.07-0.13)$ & $0.15(0.09-0.21)$ & $0.10(0.06-0.13)$ & $0.13(0.08-0.19)$ & $0.12(0.08-0.16)$ \\
\hline 180 (79.6) & 68 (75.6) & $134(81.2)$ & $61(75.3)$ & $132(76.7)$ \\
\hline $185(75.8)$ & $71(72.4)$ & $144(77.4)$ & $72(78.3)$ & $142(76.3)$ \\
\hline
\end{tabular}

\begin{tabular}{|c|c|c|c|c|c|}
\hline $\operatorname{ARR}(97.5 \% \mathrm{CI})$ & $0.10(0.07-0.13)$ & $0.15(0.09-0.21)$ & $0.10(0.06-0.13)$ & $0.13(0.08-0.19)$ & $0.12(0.08-0.16)$ \\
\hline $\begin{array}{l}\text { Proportion of patients } \\
\text { qualifying relapse- } \\
\text { free }[n(\%)]\end{array}$ & $180(79.6)$ & $68(75.6)$ & $134(81.2)$ & $61(75.3)$ & $132(76.7)$ \\
\hline $\begin{array}{l}\text { Proportion of patients } \\
\text { who remained free } \\
\text { from 3-month CDP } \\
{[n(\%)]}\end{array}$ & $185(75.8)$ & $71(72.4)$ & $144(77.4)$ & $72(78.3)$ & $142(76.3)$ \\
\hline
\end{tabular}

Qualified relapses were defined as a $\geq 2$-point increase in at least one functional system or a $\geq 1$-point increase in at least two functional systems of the EDSS, excluding bladder/bowel or cognition changes, lasting $\geq 24 \mathrm{~h}$, in the absence of fever, and preceded by $\geq 30$ days of clinical stability or improvement. ARR adjusted for time on study only. Data are mean (SD), unless otherwise stated. The CLARITY Extension data in this table covers the 96-week double-blind period and the 24-week supplemental follow-up (including the bridge between periods)

$A R R$ annualized relapse rate, $C C 7 \mathrm{mg} / \mathrm{kg}$ cladribine tablets $3.5 \mathrm{mg} / \mathrm{kg}$ in CLARITY followed by cladribine tablets $3.5 \mathrm{mg} / \mathrm{kg}$ in CLARITY Extension, $C C 8.75 \mathrm{mg} / \mathrm{kg}$ cladribine tablets $5.25 \mathrm{mg} / \mathrm{kg}$ in CLARITY followed by cladribine tablets $3.5 \mathrm{mg} / \mathrm{kg}$ in CLARITY Extension, $C P$ $3.5 \mathrm{mg} / \mathrm{kg}$ cladribine tablets $3.5 \mathrm{mg} / \mathrm{kg}$ in CLARITY followed by placebo in CLARITY Extension, $C P 5.25 \mathrm{mg} / \mathrm{kg}$ cladribine tablets $5.25 \mathrm{mg} / \mathrm{kg}$ in CLARITY followed by placebo in CLARITY Extension, CDP confirmed disability progression, $C I$ confidence interval, EDSS Expanded Disability Status Scale, $P C 3.5 \mathrm{mg} / \mathrm{kg}$ placebo in CLARITY followed by cladribine tablets $3.5 \mathrm{mg} / \mathrm{kg}$ in CLARITY Extension, $S D$ standard deviation 
Table 4 ORACLE-MS efficacy: key MRI endpoints [94]

\begin{tabular}{|c|c|c|c|}
\hline & Placebo $[n=206]$ & $\begin{array}{l}\text { Cladribine tablets } \\
3.5 \mathrm{mg} / \mathrm{kg}[n=206]\end{array}$ & $\begin{array}{l}\text { Cladribine tablets } \\
5.25 \mathrm{~kg} / \mathrm{mg} \\
{[n=204]}\end{array}$ \\
\hline \multicolumn{4}{|l|}{ Time to conversion to clinically definite MS (Poser criteria) } \\
\hline Risk reduction, $\%$ & & 67 & 62 \\
\hline $\mathrm{HR}(95 \% \mathrm{CI})$ & & $0.33(0.21-0.51)$ & $0.38(0.25-0.58)$ \\
\hline$p$ value vs. placebo & & $<0.0001$ & $<0.0001$ \\
\hline Cumulative percentage probability of clinically definite MS conversion, $\%$ & 38.0 & 14.0 & 15.9 \\
\hline \multicolumn{4}{|l|}{ New or persisting $\mathrm{T} 1 \mathrm{Gd}+$ lesions } \\
\hline Median cumulative number of lesions (IQR) & $2.0(0.0-5.0)$ & $0.0(0.0-1.0)$ & \\
\hline Treatment group comparison: cladribine/placebo, ratio $(95 \% \mathrm{CI})^{\mathrm{a}}$ & & $0.108(0.55-0.210)^{\mathrm{b}}$ & \\
\hline Risk reduction vs. placebo, $\%$ & & 89.3 & \\
\hline \multicolumn{4}{|l|}{ New or enlarging $\mathrm{T} 2$ lesions } \\
\hline Median cumulative number of lesions (IQR) & $2.0(0.0-8.0)$ & $0.0(0.0-2.0)$ & \\
\hline Treatment group comparison: cladribine/placebo, ratio $(95 \% \mathrm{CI})^{\mathrm{a}}$ & & $0.212(0.152-0.295)$ & \\
\hline Risk reduction vs. placebo, $\%$ & & 78.8 & \\
\hline \multicolumn{4}{|l|}{ Combined unique active lesions } \\
\hline Median cumulative number of lesions (IQR) & $4.0(1.0-13.5)$ & $1.0(0.0-3.0)$ & \\
\hline Treatment group comparison: cladribine/placebo, ratio $(95 \% \mathrm{CI})^{\mathrm{a}}$ & & $0.157(0.098-0.251)$ & \\
\hline Risk reduction vs. placebo, $\%$ & & 84.3 & \\
\hline
\end{tabular}

Data are for the double-blind treatment period (i.e. from randomization to the end of the double-blind period, which was at 96 weeks, or earlier if a diagnosis of MS was made)

$C I$ confidence interval, $G d+$ gadolinium-enhancing, $H R$ hazard ratio, $I Q R$ interquartile range, $M R I$ magnetic resonance imaging, $M S$ multiple sclerosis

${ }^{a}$ From the analysis of the cumulative number of lesions, using a negative binomial model with treatment, region, treatment $\times$ region, and baseline lesion count as covariates, and the log number of scans as an offset variable

${ }^{\mathrm{b}} p<0.0001$ versus placebo from the Wald Chi-square test

$3.5 \mathrm{mg} / \mathrm{kg}$ were associated with a significant risk reduction versus placebo $(67 \%)$ for conversion to CDMS (HR 0.33, 95\% CI 0.21-0.51; $p<0.0001$ ) (Table 4) [94]. Compared with placebo, patients treated with cladribine tablets $3.5 \mathrm{mg} /$ $\mathrm{kg}$ had significantly lower median numbers of new or persisting $\mathrm{T} 1 \mathrm{Gd}+$ lesions, new or enlarging $\mathrm{T} 2$ lesions, and CUA lesions $(p<0.0001)$ (Table 4) [94]. In total, 25 cladribine tablets $3.5 \mathrm{mg} / \mathrm{kg}$ and 60 placebo patients who progressed to CDMS chose to receive subsequent SC IFN- $\beta 1$ a therapy, and in these patients, $4 \%$ of those previously in the cladribine tablets $3.5 \mathrm{mg} / \mathrm{kg}$ treatment group and $3.3 \%$ of those previously in the placebo group experienced lymphopenia, suggesting that there was no additive effect of treatment switching on developing lymphopenia [94].

Diagnostic criteria for MS have been revised since enrollment of the ORACLE-MS study population [95]. More than one-third of patients in ORACLE-MS, originally considered to have clinically isolated syndrome (CIS) under the 2005 McDonald criteria [96], would receive a diagnosis of MS under the revised 2010 McDonald criteria [95, 97]. A posthoc analysis conducted in patients with CIS per the 2010 McDonald criteria $(n=393)$ was consistent with the original analysis in the ITT population: treatment with cladribine tablets $3.5 \mathrm{mg} / \mathrm{kg}(n=138)$ significantly reduced the risk of next clinical event or 3-month CDP by $63 \%$ versus placebo ( $n=134 ; p=0.0003$ ) [97]. Furthermore, in patients with MS defined per the McDonald 2010 criteria, cladribine tablets $3.5 \mathrm{mg} / \mathrm{kg}(n=68)$ significantly reduced the risk of another event or 3 -month CDP by $74 \%$ versus placebo $(n=72$; HR $0.26,95 \%$ CI $0.12-0.58 ; p=0.0009$ ) [97]. Application of the most recent 2017 McDonald criteria [98] to the ORACLEMS population would likely identify an even higher proportion of patients with RRMS [99]. In the US label, CIS is not a recommended indication for cladribine tablets [26].

\subsection{Onward (Oral cladribine added oN to IFN- $\beta$ in patients with Active Relapsing Disease): NCT00436826}

ONWARD was a 2-year, randomized, double-blind, phase IIb study assessing cladribine tablets as an add-on to IFN- $\beta$ in patients with active RMS (one or more relapses during 48 weeks of treatment with IFN- $\beta$ ) (Table 1) [100]. Under the original study protocol, two cumulative doses of cladribine tablets $(3.5 \mathrm{mg} / \mathrm{kg}$ and $5.25 \mathrm{mg} / \mathrm{kg})$ added to existing IFN- $\beta$ therapy (any form of IFN- $\beta$ ) were to be assessed. 
Following a signal related to lymphopenia with cladribine tablets $5.25 \mathrm{mg} / \mathrm{kg}$ plus IFN- $\beta$ in this study $(15 / 17$ [88.2\%] patients had grade $3 / 4$ lymphopenia $\left[<500\right.$ cells $\left./ \mathrm{mm}^{3}\right]$ ), this dose was discontinued and patients who had already been randomized to this dose continued in the trial but received IFN- $\beta$ only and were followed up for safety. The increased risk of lymphopenia when cladribine tablets are used in combination with IFN- $\beta$ is reflected in product labels, which state that concomitant treatment is not recommended [12, 26]. Under an amended protocol, patients in the ONWARD study were randomized $2: 1$ to cladribine tablets $3.5 \mathrm{mg} / \mathrm{kg}$ plus IFN- $\beta$, or placebo plus IFN- $\beta$ [100].

Eligible patients were aged 18-65 years, had RRMS or SPMS with relapses (2005 McDonald criteria [96]), received treatment with IFN- $\beta$ for $\geq 48$ consecutive weeks before screening with one or more MS relapses during that period, had clinical stability (other than relapses) during the 28 days before screening, had an EDSS score of 1.0-5.5, and had normal hematologic parameters within 28 days of baseline (day 1 of randomization) [100]. The primary outcome was safety and tolerability of cladribine tablets added to IFN- $\beta$. Secondary objectives included the following efficacy evaluations: the number of qualifying relapses over 96 weeks; time to first qualifying relapse; time to 3-month CDP; mean numbers of new $\mathrm{Gd}+\mathrm{T} 1$, active $\mathrm{T} 2$, and CUA lesions (new $\mathrm{Gd}+\mathrm{T} 1$, new or enlarging $\mathrm{T} 2$ lesions, or both, without double counting) on MRI scans at 96 weeks. As ONWARD was designed as a phase II safety study, efficacy evaluations were exploratory and were not sufficiently powered to detect intergroup differences [100].

Under the amended protocol, 172 patients were randomized and analyzed for safety and efficacy; 42 patients were randomized under the original protocol and analyzed separately for safety [100]. Here, efficacy results for the 172 patients recruited under the amended protocol are discussed. IFN- $\beta$ s administered in combination with cladribine tablets $3.5 \mathrm{mg} / \mathrm{kg}$ were SC IFN- $\beta-1 \mathrm{a} 44 \mu \mathrm{g}$ three times/ week (Rebif ${ }^{\circledR} ; n=82$ ), IM IFN- $\beta$-1a $30 \mu \mathrm{g}$ once/week (Avonex ${ }^{\circledR} ; n=30$ ), and SC IFN- $\beta-1 \mathrm{~b} 250 \mu \mathrm{g}$ every other day (Betaseron ${ }^{\circledR} /$ Betaferon $\left.^{\circledR} ; n=60\right)$ [100]. Baseline demographics were similar in the cladribine tablets $3.5 \mathrm{mg} / \mathrm{kg}$ and IFN- $\beta$ group and the placebo and IFN- $\beta$ group; mean patient age was 38.5 and 40.1 years, and gender breakdown was $67.7 \%$ and $75.0 \%$ female, respectively [100].

Cladribine tablets at a cumulative dose of $3.5 \mathrm{mg} / \mathrm{kg}$ over 2 years plus IFN- $\beta$ demonstrated a significant reduction in relapses and new $\mathrm{T} 1 \mathrm{Gd}+$, active $\mathrm{T} 2$, and CUA lesions compared with IFN- $\beta$ alone (Table 5) [100]. Patients treated with cladribine tablets $3.5 \mathrm{mg} / \mathrm{kg}$ were $63 \%$ less likely to have a qualifying relapse than patients receiving placebo and IFN- $\beta$ (relative risk $0.37,95 \%$ CI $0.22-0.63 ; p=0.001$ ) [100]. During the double-blind period, there was a significant reduction in the number of new $\mathrm{T} 1 \mathrm{Gd}+$ lesions in the cladribine tablets $3.5 \mathrm{mg} / \mathrm{kg}$ and IFN $-\beta$ group (mean 0.25 [SD 1.46]) compared with the placebo and IFN- $\beta$ group (1.27 [SD 3.39]) [100]. Patients in the cladribine tablets $3.5 \mathrm{mg} / \mathrm{kg}$ and IFN- $\beta$ group were $90 \%$ less likely to have a new T1 Gd+ lesion and 59\% less likely to have a CUA lesion compared with the placebo and IFN- $\beta$ group [100]. Fewer patients in the cladribine tablets $3.5 \mathrm{mg} / \mathrm{kg}$ and IFN- $\beta$ group experienced a first qualifying relapse $(23 / 124 ; 18.5 \%)$ versus the placebo and IFN- $\beta$ group $(16 / 48 ; 33.3 \%)$; however, the survival curves crossed, indicating that the assumptions on which the statistical analysis is based are not valid, therefore the result should be interpreted with caution [100]. The proportion of patients in the cladribine $3.5 \mathrm{mg} / \mathrm{kg}$ and IFN- $\beta$ group with confirmed EDSS progression over 2 years $(19 / 124 ; 15.3 \%)$ was similar to that in the placebo and IFN- $\beta$ group $(6 / 48 ; 12.5 \%)$ [100].

\section{Clinical Studies in RMS: Safety}

An integrated analysis of safety data from the phase III clinical trials (CLARITY, CLARITY Extension, and ORACLE-MS) and the PREMIERE registry (an observational subject registry designed to allow for further characterization of the long-term safety profile [101]) was performed to comprehensively assess the safety profile of cladribine tablets [102, 103]. The integrated analysis was performed using aggregated data with a cut-off date of 20 February 2015 [102], and subsequently updated using data gathered to May 2017 [103]. Data for patients treated with cladribine tablets $3.5 \mathrm{mg} / \mathrm{kg}$ monotherapy $(n=923 ; 3754$ patient-years to May 2017) or placebo ( $n=641 ; 2275$ patient-years $)$ in the CLARITY, CLARITY Extension, and ORACLE-MS phase III studies and the follow-up PREMIERE registry were aggregated to comprise the Monotherapy Oral Cohort. Studies that involved the use of parenteral cladribine in patients with MS, or cladribine tablets administered in combination with another DMD (the ONWARD study), were included in the All Exposed Cohort (cladribine $n=1976$ and placebo $n=802$ ) [102].

In the initial integrated analysis (cut-off February 2015), the incidence rate of treatment-emergent AEs (TEAEs) in patients receiving cladribine tablets $3.5 \mathrm{mg} / \mathrm{kg}$ as monotherapy compared with placebo-treated patients was 103.29 versus 94.26 adjusted $\mathrm{AE}$ incidence rates per 100 patientyears [102]. The most common TEAE was headache, with a similar incidence in patients exposed to cladribine tablets or placebo. Hematologic TEAEs such as lymphopenia and neutropenia were more common with cladribine tablets $3.5 \mathrm{mg} / \mathrm{kg}$ than placebo (Table 6) [102]. The updated safety analysis (cut-off date May 2017) demonstrated that AE rates remained stable, with no new major safety findings [103]. 
Table 5 ONWARD efficacy [100]

\begin{tabular}{|c|c|c|c|c|}
\hline & $\begin{array}{l}\text { Placebo/IFN } \beta \\
{[n=48]}\end{array}$ & $\begin{array}{l}\text { Cladribine tablets } 3.5 \mathrm{mg} / \\
\mathrm{kg} \text { and IFN- } \beta[n=124]\end{array}$ & Relative risk $(95 \% \mathrm{CI})^{\mathrm{a}}$ & $p$ value \\
\hline Annualized qualifying relapse rate & 0.32 & 0.12 & $0.37(0.22-0.63)$ & 0.001 \\
\hline Number of new $\mathrm{T} 1 \mathrm{Gd}+$ lesions [mean (SD)] & $1.27(3.39)$ & $0.25(1.46)$ & $0.10(0.03-0.37)$ & $<0.001^{\mathrm{b}}$ \\
\hline Total number of new T2 lesions [mean (SD)] & $3.65(6.83)$ & $2.05(4.91)$ & $0.54(0.27-1.10)$ & $0.090^{\mathrm{c}}$ \\
\hline Total number of combined unique lesions [mean (SD)] & $3.96(7.38)$ & $2.12(4.95)$ & $0.41(0.21-0.81)$ & $0.011^{\mathrm{d}}$ \\
\hline
\end{tabular}

Annualized qualifying relapse rate $=($ total number of qualifying relapses/total time on study during the double-blind period $) \times 365.25$. Qualified relapses were defined as a $\geq 2$-point increase in at least one functional system or a $\geq 1$-point increase in at least two functional systems of the EDSS, excluding bladder/bowel or cognition changes, lasting $\geq 24 \mathrm{~h}$, in the absence of fever, and preceded by $\geq 30$ days of clinical stability or improvement. $p$ value based on the Wald Chi-square test from the number of qualifying relapses using a Poisson regression model with fixed effects for the treatment group and IFN- $\beta$ treatment and with log of time on study during the double-blind period as an offset. All efficacy analyses were exploratory, as the study was not powered to detect between-group differences for any endpoint. All $p$ values $<0.05$ are considered nominally significant

CI confidence interval, EDSS Expanded Disability Status Scale, $G d+$ gadolinium-enhancing, IFN interferon, $S D$ standard deviation

${ }^{a}$ Relative risk and associated $95 \%$ CI were estimated using a negative binomial model with fixed effects for the treatment group and IFN- $\beta$ treatment, baseline $\mathrm{T} 1 \mathrm{Gd}+$ lesions as a covariate, and log of number of scans as an offset variable

${ }^{\mathrm{b}} p$ value based on the Wald Chi-square test from analysis of the total number of new T1 Gd+lesions using a negative binomial model with fixed effects for the treatment group and IFN- $\beta$ treatment, baseline T1 Gd+lesions as a covariate, and log of number of scans as an offset variable

${ }^{c} p$ value based on the Wald Chi-square test from analysis of the total number of active T2 lesions using a negative binomial model with fixed effects for the treatment group and IFN- $\beta$ treatment, with the log of number of scans as an offset variable

${ }^{\mathrm{d}} p$ value based on the Wald Chi-square test from analysis of the total number of combined unique lesions using a negative binomial model with fixed effects for the treatment group and IFN- $\beta$ treatment, baseline $\mathrm{T} 1 \mathrm{Gd}+$ lesions as a covariate, and log of number of scans as an offset variable

Lymphopenia, infections, and malignancies were three AEs analyzed within the clinical program. Lymphopenia was commonly reported among patients receiving cladribine tablets. In the CLARITY and CLARITY Extension studies, grade 3 lymphopenia (ALC 0.2 to $<0.5 \times 10^{9}$ cells $/ \mathrm{L}$ ) was experienced on at least one occasion by $25 \%$ of patients in the cladribine tablets $3.5 \mathrm{mg} / \mathrm{kg}$ treatment group; $<1 \%$ experienced grade 4 lymphopenia (ALC $<0.2 \times 10^{9}$ cells/L) at any point during the studies [102]. Analysis of patients from CLARITY and CLARITY Extension, including those also enrolled in PREMIERE, showed that lymphocyte counts steadily increased in the weeks following the nadir (observed at about 2 months after treatment initiation in each year) and had reached normal range $\left(\mathrm{ALC}>1.0 \times 10^{9} \mathrm{cells} / \mathrm{L}\right)$ by study weeks 48 and 84 in treatment years 1 and 2, respectively [64].

Incidence rates for overall infection, severe infections, infections leading to discontinuation, or opportunistic infections were comparable between the cladribine tablets $3.5 \mathrm{mg} / \mathrm{kg}$ treatment group and the placebo group. Herpes zoster was the most common herpetic infection reported in patients in the cladribine tablets $3.5 \mathrm{mg} / \mathrm{kg}$ treatment group (Table 7). Herpes zoster infections occurred most frequently during periods of grade 3/4 lymphopenia (adjusted incidence rate 4.50 per 100 patient-years, compared with 0.73 per 100 patient-years outside periods of grade 3/4 lymphopenia) [102]. For patients who are antibody-negative for varicella zoster virus (VZV), vaccination against VZV is recommended at least 4-6 weeks prior to initiation of cladribine tablets therapy. Due to the risk of active vaccine infections, cladribine therapy must not be initiated within 4-6 weeks after vaccination with live or live-attenuated vaccines. Vaccinations with live or live-attenuated vaccines during and after a treatment course (when white blood cells counts are not within normal limits) should also be avoided [26]. During the clinical development program of cladribine tablets in MS, a total of three cases of tuberculosis (TB) were reported [26]. All three cases occurred in regions where TB is endemic and in patients who were enrolled in the trials prior to implementation of a protocol amendment requiring screening for TB [26]. TB is included as an adverse reaction in the product labeling of cladribine tablets $[12,26]$.

The overall incidence of malignancies in the integrated safety analysis was 0.27 per 100 patient-years (10 events in 3754 patient-years) in patients receiving cladribine tablets $3.5 \mathrm{mg} / \mathrm{kg}$ monotherapy, and 0.13 malignancies per 100 patient-years ( 3 events in 2275 patient-years) in patients receiving placebo, as of May 2017 [26]. Malignancies in the cladribine tablets $3.5 \mathrm{mg} / \mathrm{kg}$ oral monotherapy group included melanoma $(n=2)$, basal cell carcinoma, squamous cell carcinoma, pancreatic, breast, ovarian, rectal, and papillary thyroid cancers, and bile duct adenocarcinoma $(n=1$ each) (data on file); in the placebo group, there were two cases of cervical carcinoma and one basal cell carcinoma [26]. This indicates no clustering of malignancies of any particular type and no increase in malignancies commonly 
Table 6 Integrated safety data: summary of AEs for the monotherapy oral cohort (cut-off February 2015) [102]

\begin{tabular}{|c|c|c|c|c|c|c|}
\hline & \multicolumn{3}{|c|}{ Placebo $[N=641]$} & \multicolumn{3}{|c|}{$\begin{array}{l}\text { Cladribine tablets } 3.5 \mathrm{mg} / \mathrm{kg} \\
{[N=923]}\end{array}$} \\
\hline & $n$ & $T$ & $\begin{array}{l}\text { Adj-AE per } \\
100 \mathrm{PY}\end{array}$ & $n$ & $T$ & $\begin{array}{l}\text { Adj-AE } \\
\text { per } 100 \\
\text { PY }\end{array}$ \\
\hline Number of patients with $\geq 1$ TEAE & 515 & 546.3 & 94.26 & 773 & 748.4 & 103.29 \\
\hline Number of patients with $\geq 1$ TEAE related to study drug & 291 & 1162.8 & 25.03 & 542 & 1605.5 & 33.76 \\
\hline Number of patients with $\geq 1$ serious TEAE ${ }^{a}$ & 67 & 1876.3 & 3.57 & 124 & 3096.8 & 4.00 \\
\hline Number of patients with TEAE leading to treatment discontinuation & 21 & 1993.7 & 1.05 & 67 & 3229.0 & 2.07 \\
\hline Number of patients with $\geq 1$ severe TEAE reported in $\geq 2$ patients & 57 & 1912.5 & 2.98 & 115 & 3111.2 & 3.70 \\
\hline Number of patients with TEAE leading to death & 5 & 2024.7 & 0.25 & 9 & 3431.0 & 0.26 \\
\hline \multicolumn{7}{|c|}{ Most commonly reported TEAEs (Adj-AE per $100 P Y$ of $\geq 1.0$ in either group $)^{b}$} \\
\hline Nervous system disorders & 226 & 1429.5 & 15.81 & 327 & 2346.7 & 13.93 \\
\hline Headache & 144 & 1631.9 & 8.82 & 230 & 2641.9 & 8.71 \\
\hline Dizziness & 36 & 1944.4 & 1.85 & 47 & 3268.0 & 1.44 \\
\hline MS relapse ${ }^{c}$ & 11 & 2014.0 & 0.55 & 21 & 3404.9 & 0.62 \\
\hline Gastrointestinal disorders & 197 & 1454.9 & 13.54 & 278 & 2482.0 & 11.20 \\
\hline Nausea & 62 & 1845.6 & 3.36 & 86 & 3134.4 & 2.74 \\
\hline Diarrhea & 44 & 1915.9 & 2.30 & 68 & 3202.0 & 2.12 \\
\hline Abdominal pain, upper & 22 & 1969.2 & 1.12 & 42 & 3283.1 & 1.28 \\
\hline Toothache & 22 & 1957.5 & 1.12 & 35 & 3335.8 & 1.05 \\
\hline Abdominal pain & 23 & 1966.2 & 1.17 & 30 & 3346.2 & 0.90 \\
\hline Constipation & 22 & 1968.7 & 1.12 & 24 & 3368.3 & 0.71 \\
\hline Vomiting & 24 & 1982.6 & 1.21 & 21 & 3363.7 & 0.62 \\
\hline Blood and lymphatic system disorders & 47 & 1901.6 & 2.47 & 276 & 2543.4 & 10.85 \\
\hline Lymphopenia & 21 & 1985.0 & 1.06 & 217 & 2731.8 & 7.94 \\
\hline Leukopenia & 8 & 2008.4 & 0.40 & 43 & 3276.9 & 1.31 \\
\hline Neutropenia & 4 & 2015.0 & 0.20 & 27 & 3362.8 & 0.80 \\
\hline Musculoskeletal and connective tissue disorders & 153 & 1608.0 & 9.51 & 245 & 2654.5 & 9.23 \\
\hline Back pain & 46 & 1890.0 & 2.43 & 102 & 3115.8 & 3.27 \\
\hline Arthralgia & 38 & 1938.8 & 1.96 & 63 & 3236.0 & 1.95 \\
\hline Pain in extremity & 33 & 1965.6 & 1.68 & 50 & 3283.6 & 1.52 \\
\hline Myalgia & 21 & 1966.3 & 1.07 & 28 & 3356.9 & 0.83 \\
\hline Musculoskeletal pain & 16 & 1989.1 & 0.80 & 19 & 3375.9 & 0.56 \\
\hline General disorders and administration site conditions & 168 & 1558.5 & 10.78 & 213 & 2717.1 & 7.84 \\
\hline Influenza-like illness & 61 & 1857.4 & 3.28 & 75 & 3167.6 & 2.37 \\
\hline Fatigue & 47 & 1897.2 & 2.48 & 54 & 3252.1 & 1.66 \\
\hline Pyrexia & 20 & 1980.8 & 1.01 & 36 & 3341.5 & 1.08 \\
\hline Asthenia & 25 & 1941.8 & 1.29 & 33 & 3311.5 & 1.00 \\
\hline Investigations & 83 & 1802.4 & 4.61 & 145 & 2939.6 & 4.93 \\
\hline Lymphocyte count decreased & 2 & 2023.1 & 0.10 & 26 & 3337.4 & 0.78 \\
\hline Psychiatric disorders & 85 & 1787.8 & 4.75 & 121 & 3009.3 & 4.02 \\
\hline Insomnia & 32 & 1938.7 & 1.65 & 46 & 3285.5 & 1.40 \\
\hline Depression & 23 & 1960.6 & 1.17 & 46 & 3298.1 & 1.39 \\
\hline Anxiety & 12 & 2002.3 & 0.60 & 37 & 3312.1 & 1.12 \\
\hline Respiratory, thoracic, and mediastinal disorders & 95 & 1770.8 & 5.36 & 118 & 3065.2 & 3.85 \\
\hline Oropharyngeal pain & 35 & 1929.2 & 1.81 & 44 & 3278.8 & 1.34 \\
\hline Cough & 27 & 1968.3 & 1.37 & 34 & 3336.6 & 1.02 \\
\hline Vascular disorders & 45 & 1909.6 & 2.36 & 72 & 3231.2 & 2.23 \\
\hline Hypertension & 25 & 1965.3 & 1.27 & 35 & 3338.5 & 1.05 \\
\hline
\end{tabular}


Table 6 (continued)

\begin{tabular}{|c|c|c|c|c|c|c|}
\hline & \multicolumn{3}{|c|}{ Placebo $[N=641]$} & \multicolumn{3}{|c|}{$\begin{array}{l}\text { Cladribine tablets } 3.5 \mathrm{mg} / \mathrm{kg} \\
{[N=923]}\end{array}$} \\
\hline & $n$ & $T$ & $\begin{array}{l}\text { Adj-AE per } \\
100 \text { PY }\end{array}$ & $n$ & $T$ & $\begin{array}{l}\text { Adj-AE } \\
\text { per } 100 \\
\text { PY }\end{array}$ \\
\hline Ear and labyrinth disorders & 35 & 1930.6 & 1.81 & 53 & 3269.0 & 1.62 \\
\hline Vertigo & 22 & 1966.4 & 1.12 & 35 & 3317.9 & 1.05 \\
\hline Injury, poisoning, and procedural complications & 81 & 1830.4 & 4.43 & 115 & 3090.3 & 3.72 \\
\hline Fall & 13 & 1985.9 & 0.65 & 24 & 3371.1 & 0.71 \\
\hline \multicolumn{7}{|c|}{ Most commonly reported serious $T E A E s^{\mathrm{a}}$ (Adj-AE per $100 P Y$ of $\geq 0.10$ in either group) } \\
\hline Blood creatine phosphokinase increased & 4 & 2022.6 & 0.20 & 7 & 3414.4 & 0.21 \\
\hline Pneumonia & 3 & 2019.7 & 0.15 & 6 & 3403.4 & 0.18 \\
\hline Uterine leiomyoma & 2 & 2020.9 & 0.10 & 5 & 3409.7 & 0.15 \\
\hline Lymphopenia & 0 & 0 & 0 & 4 & 3421.4 & 0.12 \\
\hline Urinary tract infection & 1 & 2024.4 & 0.05 & 4 & 3419.4 & 0.12 \\
\hline
\end{tabular}

If a patient has multiple events, the time to the first event is considered. For a patient with no event, the time is censored at the last follow-up time for that patient. Adj-AE per $100 \mathrm{PY}$ is the time-adjusted AE incidence rate that can be interpreted as the number of events occurring in 100 patient-years

Adj adjusted, $A E$ adverse event, $P Y$ patient-years, SMPC Summary of Product Characteristics, TEAE treatment-emergent adverse event, $n$ number of patients with events, $T$ total patient time on study in years

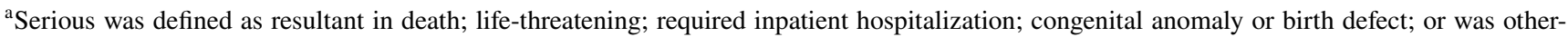
wise considered as medically important

${ }^{\mathrm{b}}$ System organ class and preferred terms are presented in descending order of Adj-AE per $100 \mathrm{PY}$ rate in the cladribine tablets $3.5 \mathrm{mg} / \mathrm{kg}$ group. The EU SMPC lists rash and alopecia as common TEAEs for cladribine tablets $3.5 \mathrm{mg} / \mathrm{kg}$ [12]. The Adj-AEs per 100 PY are alopecia 0.60 vs. 0.40 , for placebo; rash 0.60 vs. 0.45 , for placebo

'The preferred term 'Multiple sclerosis relapse' was reported in the PREMIERE study, where relapse was not an efficacy endpoint

associated with immunosuppression (hematologic, virally induced, or non-melanoma skin cancers) in patients treated with cladribine tablets $3.5 \mathrm{mg} / \mathrm{kg}$ [102]. Meta-analysis using CLARITY data showed that the zero incidence of malignancies in the placebo group was significantly lower than the expected rate seen in placebo groups in other trials in similar RMS populations, while the malignancy rate with cladribine tablets ( $n=3$ in the cladribine tablets $3.5 \mathrm{mg} / \mathrm{kg}$ group [65]) was not significantly different to rates in the active treatment groups in trials of other DMDs [104]. Additionally, results from epidemiologic analyses showed no increase in the incidence of malignancies in the clinical trial program compared with matched reference populations (standardized incidence ratio [SIR] $0.91,95 \%$ CI $0.41-1.75$, for the $3.5 \mathrm{mg} / \mathrm{kg}$ oral monotherapy cohort vs. GLOBOCAN matched reference population; SIR 0.44 , 95\% CI 0.13-1.41, for placebo vs. reference population) [105]. Analysis of malignancy rates over time showed that the incidence of malignancies remained constant in follow-up for years $1-4$ ( 0.29 per 100 patientyears in the oral monotherapy cohort, as of the February 2015 cut-off $)$ and years 5-8+(0.28 per 100 patient-years $)$. In contrast, the malignancy rates in the placebo group were higher in years $5-8+(0.60$ per 100 patient-years $)$ than years 1-4 (0.06 per 100 patient-years), although the overall number of events was small [102]. This suggests that the low level of malignancies observed in the placebo group in the short-term was a chance observation.

In addition to continued monitoring of the safety population described above, a long-term, multi-country, prospective, observational post-authorization safety study is underway to further characterize the long-term safety profile of cladribine tablets [102]. The CLARION study is designed to follow 8000 patients who are starting treatment with cladribine tablets or fingolimod (an oral comparator that depletes lymphocytes) for a period of 10 years to evaluate AEs [102, 106].

\section{Discussion}

Despite the recent approval of several new DMDs for RMS, there still remains a need for therapies that provide improved efficacy, address issues with treatment adherence and compliance, reduce the need for invasive procedures and intensive monitoring, and avoid the potential for treatment-related fatigue observed with daily long-term administration. Due to the observed efficacy of parenteral cladribine in earlier pilot studies of patients with MS, the cladribine tablets formulation was designed and developed to address some of these needs. 
Table 7 Integrated safety data: summary of infections and infestations for the monotherapy oral cohort (cut-off February 2015) [102]

\begin{tabular}{|c|c|c|c|c|c|c|}
\hline & \multicolumn{3}{|c|}{ Placebo $[N=641]$} & \multicolumn{3}{|c|}{$\begin{array}{l}\text { Cladribine tablets } 3.5 \mathrm{mg} / \\
\mathrm{kg}[N=923]\end{array}$} \\
\hline & $n$ & Total PY & $\begin{array}{l}\text { Adj-AE } \\
\text { per } 100 \\
\text { PY }\end{array}$ & $n$ & Total PY & $\begin{array}{l}\text { Adj-AE } \\
\text { per } 100 \\
\text { PY }\end{array}$ \\
\hline $\begin{array}{l}\text { Most commonly reported TEAEs in SOC infections and infestations }{ }^{\mathrm{a}} \text { (Adj-AE per } \\
100 \mathrm{PY} \text { of } \geq 1.0 \text { in either group) }\end{array}$ & 314 & 1160.8 & 27.05 & 478 & 1917.5 & 24.93 \\
\hline Nasopharyngitis & 97 & 1764.5 & 5.50 & 158 & 2951.0 & 5.35 \\
\hline Upper respiratory tract infection & 61 & 1869.1 & 3.26 & 109 & 3112.0 & 3.50 \\
\hline Influenza & 51 & 1898.1 & 2.69 & 87 & 3169.5 & 2.74 \\
\hline Bronchitis & 22 & 1964.4 & 1.12 & 55 & 3234.1 & 1.70 \\
\hline Urinary tract infection & 46 & 1916.8 & 2.40 & 55 & 3249.7 & 1.69 \\
\hline Herpes zoster & 4 & 2019.0 & 0.20 & 28 & 3360.2 & 0.83 \\
\hline Pharyngitis & 31 & 1961.4 & 1.58 & 27 & 3348.0 & 0.81 \\
\hline Rhinitis & 22 & 1962.3 & 1.12 & 24 & 3354.0 & 0.72 \\
\hline $\begin{array}{l}\text { Serious TEAEs in SOC infections and infestations }{ }^{\mathrm{b}} \text { (Adj-AE of } \geq 0.05 \text { in either } \\
\text { group) }\end{array}$ & 10 & 2003.4 & 0.50 & 23 & 3357.6 & 0.69 \\
\hline Appendicitis & 2 & 2023.5 & 0.10 & 1 & 3426.8 & 0.03 \\
\hline Chronic hepatitis C & 1 & 2019.4 & 0.05 & 0 & 3432.7 & 0 \\
\hline Chronic sinusitis & 1 & 2024.1 & 0.05 & 0 & 3432.7 & 0 \\
\hline Erysipelas & 1 & 2022.1 & 0.05 & 0 & 3432.7 & 0 \\
\hline Herpes zoster & 0 & 2026.0 & 0 & 2 & 3425.6 & 0.06 \\
\hline Myocarditis bacterial & 1 & 2024.2 & 0.05 & 0 & 3432.7 & 0 \\
\hline Pneumonia & 3 & 2019.7 & 0.15 & 6 & 3403.4 & 0.18 \\
\hline Pyelonephritis & 0 & 2026.0 & 0 & 2 & 3423.1 & 0.06 \\
\hline Urethral abscess & 1 & 2025.9 & 0.05 & 1 & 3430.3 & 0.03 \\
\hline Urinary tract infection & 1 & 2024.4 & 0.05 & 4 & 3419.4 & 0.12 \\
\hline $\begin{array}{l}\text { Infections and infestations SOC leading to treatment discontinuation (Adj-AE } \\
\text { of } \geq 0.01 \text { in either group) }\end{array}$ & 3 & 2020.8 & 0.15 & 4 & 3415.5 & 0.12 \\
\hline Hepatitis B & 0 & 2026.0 & 0 & 1 & 3427.9 & 0.03 \\
\hline Herpes zoster & 0 & 2026.0 & 0 & 1 & 3424.8 & 0.03 \\
\hline Pneumonia bacterial & 0 & 2026.0 & 0 & 1 & 3428.2 & 0.03 \\
\hline Urinary tract infection & 0 & 2026.0 & 0 & 1 & 3432.6 & 0.03 \\
\hline Appendicitis & 1 & 2025.8 & 0.05 & 0 & 3432.7 & 0 \\
\hline Gardnerella infection & 1 & 2025.8 & 0.05 & 0 & 3432.7 & 0 \\
\hline Varicella & 1 & 2021.0 & 0.05 & 0 & 3432.7 & 0 \\
\hline Severe infection $^{c}$ (Adj-AE of $\geq 0.05$ in any group) & 17 & 1983.4 & 0.86 & 28 & 3336.2 & 0.84 \\
\hline Pneumonia & 3 & 2109.7 & 0.15 & 6 & 3403.4 & 0.18 \\
\hline Urinary tract infection & 2 & 2023.4 & 0.10 & 4 & 3419.4 & 0.12 \\
\hline Herpes zoster & 1 & 2024.4 & 0.05 & 3 & 3424.1 & 0.09 \\
\hline Gastroenteritis & 0 & 2026.0 & 0 & 2 & 3423.8 & 0.06 \\
\hline Pyelonephritis & 0 & 2026.0 & 0 & 2 & 3423.1 & 0.06 \\
\hline Opportunistic infections ${ }^{\mathrm{d}}$ & 23 & 1965.5 & 1.17 & 36 & 3321.9 & 1.08 \\
\hline Axillary candidiasis & 1 & 2018.3 & 0.05 & 0 & 3432.7 & 0 \\
\hline Fungal infection & 2 & 2023.4 & 0.10 & 8 & 3398.3 & 0.24 \\
\hline Fungal skin infection & 2 & 2018.4 & 0.10 & 3 & 3430.8 & 0.09 \\
\hline Mastitis fungal & 1 & 2025.6 & 0.05 & 0 & 3432.7 & 0 \\
\hline Onychomycosis & 3 & 2023.1 & 0.15 & 4 & 3419.0 & 0.12 \\
\hline Oral candidiasis & 1 & 2021.6 & 0.05 & 1 & 3431.0 & 0.03 \\
\hline Oral fungal infection & 2 & 2013.9 & 0.10 & 1 & 3431.5 & 0.03 \\
\hline Pulmonary tuberculosis & 0 & 2026.0 & 0 & 1 & 3429.6 & 0.03 \\
\hline
\end{tabular}


Table 7 (continued)

\begin{tabular}{|c|c|c|c|c|c|c|}
\hline & \multicolumn{3}{|c|}{ Placebo $[N=641]$} & \multicolumn{3}{|c|}{$\begin{array}{l}\text { Cladribine tablets } 3.5 \mathrm{mg} / \\
\mathrm{kg}[N=923]\end{array}$} \\
\hline & $n$ & Total PY & $\begin{array}{l}\text { Adj-AE } \\
\text { per } 100 \\
\text { PY }\end{array}$ & $n$ & Total PY & $\begin{array}{l}\text { Adj-AE } \\
\text { per } 100 \\
\text { PY }\end{array}$ \\
\hline Skin candida & 1 & 2025.4 & 0.05 & 0 & 3432.7 & 0 \\
\hline Tonsilitis fungal & 1 & 2022.0 & 0.05 & 0 & 3432.7 & 0 \\
\hline Tuberculosis & 0 & 2026.0 & 0 & 1 & 3432.7 & 0.03 \\
\hline Upper respiratory fungal infection & 0 & 2026.0 & 0 & 1 & 3431.7 & 0.03 \\
\hline Urinary tract infection fungal & 0 & 2026.0 & 0 & 1 & 3424.1 & 0.03 \\
\hline Vulvovaginal candidiasis & 3 & 2013.3 & 0.15 & 7 & 3416.9 & 0.20 \\
\hline Vulvovaginal mycotic infection & 7 & 2016.4 & 0.35 & 9 & 3402.0 & 0.26 \\
\hline Herpetic infections & 19 & 1969.9 & 0.96 & 60 & 3262.7 & 1.84 \\
\hline Herpes zoster & 4 & 2019.0 & 0.20 & 28 & 3360.2 & 0.83 \\
\hline Oral herpes & 11 & 1996.9 & 0.55 & 20 & 3381.3 & 0.59 \\
\hline Herpes simplex & 1 & 2018.1 & 0.05 & 5 & 3416.6 & 0.15 \\
\hline Herpes virus infection & 1 & 2020.6 & 0.05 & 4 & 3416.9 & 0.12 \\
\hline Varicella & 2 & 2020.6 & 0.10 & 3 & 3422.6 & 0.09 \\
\hline Herpes zoster disseminated & 1 & 2023.7 & 0.05 & 2 & 3427.5 & 0.06 \\
\hline Genital herpes & 0 & 2026.0 & 0 & 1 & 3429.0 & 0.03 \\
\hline Herpes zoster ${ }^{\mathrm{e}}$ & 4 & 2017.7 & 0.20 & 29 & 3356.2 & 0.86 \\
\hline Herpes zoster & 4 & 2019.0 & 0.20 & 28 & 3360.2 & 0.83 \\
\hline Herpes zoster disseminated & 1 & 2023.7 & 0.05 & 2 & 3427.5 & 0.06 \\
\hline
\end{tabular}

If a patient has multiple events, the time to first event is considered. For a patient with no event the time is censored at the last follow-up time for that patient

Adj adjusted, $A E$ adverse event, $n$ number of patients with events, $H L T$ higher level term, MedDRA Medical Dictionary for Regulatory Activities, $P T s$ preferred terms, $P Y$ patient-years, $S O C$ system organ class, TEAEs treatment-emergent adverse event, Total $P Y$ total patient time on study in years

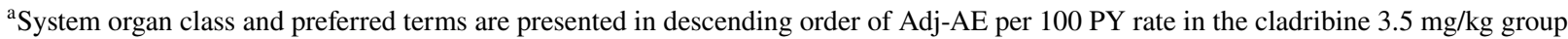

b'Serious' was defined as resultant in death; life-threatening; required inpatient hospitalization; congenital anomaly or birth defect; or was otherwise considered as medically important

'Severe infection is a custom grouping defined by any serious or severe event belonging to the MedDRA SOC 'Infections and Infestations'

${ }^{\mathrm{d}}$ Medical Concept Opportunistic Infection is a custom query containing PTs belonging to the medical concept of opportunistic infections, excluding the PTs belonging to the HLT 'Herpes viral infections'

'Medical concept herpetic infection, which is a custom grouping defined by PTs with the term 'herpes zoster'

Cladribine tablets are generally approved for the treatment of patients with RMS; however, indication wordings differ in several countries based on the individual assessment of the same clinical data by regulatory agencies. In some regions, including the EU and Switzerland, cladribine tablets are approved for use in adult patients with highly active disease $[12,107]$, whereas in other countries, including Canada and Australia, cladribine tablets are approved for the treatment of patients with RRMS [108, 109]. In the US, cladribine tablets are approved in adults with RMS, including RRMS and active SPMS, and are generally recommended for patients who have had an inadequate response to, or are unable to tolerate, an alternate drug indicated for MS [26].

In phase II and III clinical trials, cladribine tablets have demonstrated efficacy over placebo across the RMS spectrum, from treatment-naïve to treatment-experienced patients, and from patients with early MS to those with highly active disease. In the ORACLE-MS study, cladribine tablets reduced the risk of conversion from CIS to CDMS [97]. In patients with a confirmed diagnosis of RRMS in the CLARITY study, significant reductions in both clinical and MRI activity with cladribine tablets led to a significantly higher proportion of patients attaining NEDA compared with placebo patients [65]. This efficacy was maintained across all subgroups evaluated, with patients with HDA at baseline achieving the greatest improvements in NEDA rates compared with placebo [88]. Furthermore, patients with active, as evidenced by one or more relapses within 12 months of study entry, SPMS, as defined by EDSS $\geq 3.5$, achieved similar efficacy results to the subgroup without SPMS [87]. 
These findings are encouraging, as progressive forms of MS have historically been more difficult to manage and DMDs have often been found to be less efficacious in these cohorts $[83,110]$. CLARITY Extension showed that the efficacy observed in CLARITY was durable - the magnitude of suppression of clinical and MRI activity was sustained, and the proportion of patients with NEDA remained high, even in patients who did not receive additional active treatment with cladribine tablets (those who were randomized to placebo in the extension study, after receiving cladribine tablets $3.5 \mathrm{mg} /$ $\mathrm{kg}$ in CLARITY) [66, 91]. Therefore, further treatment in years 3 and 4 does not appear to be required $[12,26]$ and is not recommended based on current evidence [26]. The efficacy and safety of treatment re-initiation beyond year 4 has not been investigated.

The development program of cladribine tablets has resulted in a comprehensive characterization of its safety profile, which includes up to 10 years' follow-up in some patients [111] and more than 12,000 patient-years of follow-up overall (for MS patients receiving oral or parenteral cladribine or placebo), including 9509 patient-years' exposure to cladribine in any formulation at any dosage, and $>3700$ patients-years' follow-up (as of May 2017) for patients receiving cladribine tablets $3.5 \mathrm{mg} / \mathrm{kg}$ monotherapy in CLARITY, CLARITY EXTENSION, ORACLE-MS, and the PREMIERE registry [103]. In these clinical studies, lymphopenia was the most common TEAE, occurring more frequently with cladribine tablets $3.5 \mathrm{mg} / \mathrm{kg}$ compared with placebo as expected due to the mechanism of action of cladribine tablets. The majority of patients experienced grade 1 or 2 lymphopenia; grade 3 lymphopenia was observed in approximately $25 \%$ of patients, and $<1 \%$ of patients experienced grade 4 lymphopenia at any time over 2 years of treatment [102]. Lymphocyte recovery began within weeks after each treatment course in years 1 and 2, and stabilized on return to baseline [64]. There was no evidence of B-cell hyper-repopulation, which has been observed with alemtuzumab (which depletes lymphocytes and has a different proposed MOA, targeting the CD52 epitope) and has been speculated to mediate autoimmune adverse effects (recorded in $>20 \%$ of patients treated with alemtuzumab, most commonly thyroid disease) $[112,113]$. The gradual recovery of lymphocyte populations following cladribine tablets occurs without triggering secondary autoimmunity [102]. In patients receiving cladribine tablets, no increase in opportunistic infections was shown. Herpes zoster, oral herpes, and TB were identified as adverse reactions with cladribine tablets [102]. Given the observed increase in herpes zoster cases during periods of grade 3/4 lymphopenia, the product label carries a recommendation to administer antiherpes prophylaxis if a patient's lymphocyte count drops below 200 cells $/ \mu \mathrm{L}$ (i.e. grade 4 lymphopenia, defined as ALC $<0.2 \times 10^{9}$ cells/L) $[12,26]$. Analysis of clinical trial data showed an imbalance in the number of malignancies between cladribine tablets and placebo; however, the incidence was not dose-related, did not increase over time, and there was no clustering of malignancies of any particular type. Malignancies are considered a potential risk with cladribine because of the limited number of observations possible in a phase III study. The USPI includes a boxed warning stating that cladribine tablets may increase the risk of malignancy [26], and this potential risk is being further examined in a large post-approval study.

Most DMDs can be classified as maintenance therapies, based on their dosing regimens [15-23, 114]. Maintenance therapies are defined as being administered continuously without an intended interruption in dosing, because clinical efficacy is tightly linked to the period of dosing. The effects of these drugs are closely related to their short half-lives and pharmacokinetic and pharmacodynamic profiles; therefore, while some need to be administered more frequently than others, all require regular dosing. Over the past 30 years, multiple maintenance DMDs have been approved for the treatment of MS; however, the continuous immunosuppression of maintenance therapies may interfere with immune surveillance [115].

Drugs with MOA-producing effects that persist long after the drug is eliminated from the body provide an alternative to ongoing maintenance therapy. Cladribine tablets are postulated to be an immune reconstitution therapy (IRT) [64, 116]. Characteristics of IRTs include transient reductions of B and T lymphocyte counts and/or select lymphocyte subtypes, followed by a recovery period during which cells gradually repopulate and immune function is restored. The reconstituted lymphocyte population is hypothesized to be less autoreactive towards the CNS component, resulting in prolonged efficacy, as demonstrated in the cladribine tablets clinical studies [47, 48, 66, 91]. In these studies, there was no rebound or return of clinical or MRI activity even after recovery of lymphocyte counts, and this is also consistent with a qualitative change in the adaptive immune response after treatment with cladribine tablets [64].

Cladribine tablets are the first oral MS therapy with a non-continuous dosing regimen, with extremely short treatment courses. This may be beneficial to patients, since the small total number of treatment days could potentially improve treatment adherence $[117,118]$. In a survey designed to assess the state of MS care in the US and EU, $51 \%$ (total $N=982$ ) of patients who self-identified as having MS reported skipping doses, and the most common reason given was 'forgot' (43\%) [119]. Furthermore, patients receiving long-term therapy for MS often experience treatment fatigue, leading to a decline in adherence over time [120]. Studies have found that the serious consequences of non-adherence may include a greater risk of relapse or progression of disease compared with patients who adhere to 
treatment [121]. The dosing regimen of cladribine tablets limits the potential for non-adherence, which may reduce the risk of relapse and disease progression in real-world settings. In addition, the short and non-continuous treatment regimen may allow for the planning of life events, including pregnancy; cladribine tablets allow for pregnancy 6 months after the last dose of medication has been administered [12, 26].

\section{Conclusion}

Important therapeutic advances in the past several years have provided numerous therapeutic options for patients with MS, allowing selection depending on their particular disease characteristics, expressed desires, and lifestyle choices. The recent introduction of cladribine tablets provides a new high-efficacy therapeutic option for treating patients with MS, with a low treatment and monitoring burden. In clinical studies, cladribine tablets $(3.5 \mathrm{mg} / \mathrm{kg}$ over 2 years) have demonstrated efficacy across the RMS spectrum: from early MS to patients with RMS, including those with HDA. Potentially due to the molecule's unique proposed MOA, cladribine tablets provide durable efficacy, with a maximum of 20 total days of treatment over 2 years. Cladribine has an established safety and tolerability profile, with a clinical development program that included more than 12,000 patient-years' overall clinical and observational trial experience (all formulations and dosages), including more than 3700 patient-years for patients receiving cladribine tablets at the approved dosage ( $3.5 \mathrm{mg} / \mathrm{kg}$ taken over 2 years). Furthermore, cladribine tablets' weight-based and unique posology provides an alternative dosing schedule that allows for reduced treatment and management burden for patients and providers. This new addition to the existing arsenal of DMDs provides another treatment option to further tailor disease management in patients with MS.

Acknowledgements Writing and editorial support for the preparation of this manuscript was provided by Kindiya Geghman, Ph.D., and Nick White of Ashfield Healthcare (New York, NY, USA). EMD Serono, Inc., Rockland, MA, USA, an affiliate of Merck KGaA, Darmstadt, Germany, reviewed and provided feedback on the manuscript. The authors had full control of the manuscript and provided their final approval of all content.

\section{Declarations}

Funding Funding for writing and editorial support was provided by EMD Serono, Inc., Rockland, MA, USA, an affiliate of Merck KGaA, Darmstadt, Germany.

Conflict of interest Kottil Rammohan received honoraria for lectures and steering committee meetings from EMD Serono, Inc., an affiliate of Merck KGaA, Darmstadt, Germany, Biogen, Sanofi-Aventis, Genzyme, Novartis, Teva Neurosciences, Acorda, and Roche/Genentech.
Patricia K. Coyle received consultancy fees from Accordant, Actelion, Alexion, Bayer, Biogen, Celgene, Genentech/Roche, Novartis, Sanofi Genzyme, EMD Serono, Inc., an affiliate of Merk KGaA, Darmstadt, Germany, and TG Therapeutics, and also received research grants from Actelion Pharmaceuticals, Inc., Alkermes, Genentech/Roche, MedDay Pharmaceuticals, NINDS, and Novartis Pharmaceuticals. Elke Sylvester is an employee of Merck KGaA, Darmstadt, Germany. Andrew Galazka is an employee of Ares Trading SA, Switzerland, an affiliate of Merck KGaA, Darmstadt, Germany. Fernando Dangond is an employee of EMD Serono Research \& Development Institute, Inc., Billerica, MA, USA, an affiliate of Merck KGaA, Darmstadt, Germany. Megan Grosso is an employee of EMD Serono, Inc., Rockland, MA, USA, an affiliate of Merck KGaA, Darmstadt, Germany. Thomas P. Leist received consultancy fees or clinical research grants from Alkermes, Bayer, Biogen, EMD Serono, Inc., an affiliate of Merck KGaA, Darmstadt, Germany, Genentech, Genzyme, and Novartis.

Ethics approval Not applicable.

Consent to participate Not applicable.

Consent for publication Not applicable.

Availability of data and material Not applicable.

Code availability Not applicable.

Author contributions All authors contributed to the drafting of the manuscript and revising it critically for important intellectual content.

Open Access This article is licensed under a Creative Commons Attribution-NonCommercial 4.0 International License, which permits any non-commercial use, sharing, adaptation, distribution and reproduction in any medium or format, as long as you give appropriate credit to the original author(s) and the source, provide a link to the Creative Commons licence, and indicate if changes were made. The images or other third party material in this article are included in the article's Creative Commons licence, unless indicated otherwise in a credit line to the material. If material is not included in the article's Creative Commons licence and your intended use is not permitted by statutory regulation or exceeds the permitted use, you will need to obtain permission directly from the copyright holder. To view a copy of this licence, visit http://creativecommons.org/licenses/by-nc/4.0/.

\section{References}

1. Browne P, Chandraratna D, Angood C, Tremlett H, Baker C, Taylor BV, et al. Atlas of multiple sclerosis 2013: a growing global problem with widespread inequity. Neurology. 2014;83(11):1022-4. https://doi.org/10.1212/WNL.0000000000 000768 .

2. GBD 2016 Multiple Sclerosis Collaborators. Global, regional, and national burden of multiple sclerosis 1990-2016: a systematic analysis for the Global Burden of Disease Study 2016. Lancet Neurol. 2019;18(3):269-85. https://doi.org/10.1016/S1474 $-4422(18) 30443-5$.

3. Wallin MT, Culpepper WJ, Campbell J, Nelson LM, LangerGould A, Marrie RA et al. The prevalence of multiple sclerosis in the United States: a population-based healthcare database approach. Paris, France: European Committee for Treatment and Research in Multiple Sclerosis (ECTRIMS); 25-28 October 2017. p 344. 
4. National Multiple Sclerosis Society. Relapsing-remitting MS. https://www.nationalmssociety.org/What-is-MS/Types-of-MS/ Relapsing-remitting-MS. Accessed 24 Jul 2020.

5. Miller A, Dishon S. Health-related quality of life in multiple sclerosis: the impact of disability, gender and employment status. Qual Life Res. 2006;15(2):259-71. https://doi.org/10.1007/s1113 6-005-0891-6.

6. Owens GM. Economic burden of multiple sclerosis and the role of managed care organizations in multiple sclerosis management. Am J Manag Care. 2016;22(6 Suppl):s151-s158158.

7. Tilling K, Lawton M, Robertson N, Tremlett H, Zhu F, Harding $\mathrm{K}$, et al. Modelling disease progression in relapsing-remitting onset multiple sclerosis using multilevel models applied to longitudinal data from two natural history cohorts and one treated cohort. Health Technol Assess. 2016;20(81):1-48. https://doi. org/10.3310/hta20810.

8. Dobson R, Dassan P, Roberts M, Giovannoni G, Nelson-Piercy C, Brex PA. UK consensus on pregnancy in multiple sclerosis: 'Association of British Neurologists' guidelines. Pract Neurol. 2019;19(2):106-14. https://doi.org/10.1136/practneurol-2018002060 .

9. Burkill S, Vattulainen P, Geissbuehler Y, Sabido Espin M, Popescu C, Suzart-Woischnik K, et al. The association between exposure to interferon-beta during pregnancy and birth measurements in offspring of women with multiple sclerosis. PLoS One. 2019;14(12):e0227120. https://doi.org/10.1371/journ al.pone.0227120.

10. Hellwig K, Geissbuehler Y, Sabido M, Popescu C, Adamo A, Klinger J, et al. Pregnancy outcomes in interferon-beta-exposed patients with multiple sclerosis: results from the European Interferon-beta Pregnancy Registry. J Neurol. 2020. https://doi. org/10.1007/s00415-020-09762-y.

11. European Medicines Agency. Rebif - Procedural steps taken and scientific information after the authorisation. Amsterdam, The Netherlands. 2020. https://www.ema.europa.eu/en/documents/ procedural-steps-after/rebif-epar-procedural-steps-taken-scien tific-information-after-authorisation_en.pdf. Accessed 11 Feb 2020.

12. Mavenclad [summary of product characteristics]. Amsterdam: Merck Europe B.V.; 2020.

13. Sandberg-Wollheim M, Neudorfer O, Grinspan A, WeinstockGuttman B, Haas J, Izquierdo G, et al. Pregnancy outcomes from the branded glatiramer acetate pregnancy database. Int J MS Care. 2018;20(1):9-14. https://doi.org/10.7224/1537-2073.2016-079.

14. Herbstritt S, Langer-Gould A, Rockhoff M, Haghikia A, Queisser-Wahrendorf A, Gold R, et al. Glatiramer acetate during early pregnancy: a prospective cohort study. Mult Scler. 2016;22(6):810-6. https://doi.org/10.1177/1352458515623366.

15. Copaxone [package insert]. North Wales, PA: Teva Pharmaceuticals USA, Inc.; 2016.

16. Plegridy [package insert]. Cambridge, MA: Biogen Inc.; 2014.

17. Rebif [package insert]. Rockland, MA: EMD Serono, Inc.; 2015.

18. Avonex [package insert]. Cambridge, MA: Biogen Inc.; 2016.

19. Betaseron [package insert]. Whippany, NJ: Bayer HealthCare Pharmaceuticals; 2018.

20. Aubagio [package insert]. Cambridge, MA: Genzyme Corporation; 2016.

21. Gilenya [package insert]. Stein, Switzerland: Novartis Phama Stein AG; 2019.

22. Tecfidera [package insert]. Cambridge, MA: Biogen Inc.; 2017.

23. Tysabri [package insert]. Cambridge, MA: Biogen Inc.; 2018.

24. Lemtrada [package insert]. Cambridge, MA: Genzyme Corporation; 2019.

25. Ocrevus [package insert]. San Francisco, CA: Genentech, Inc.; 2018.
26. Mavenclad [package insert]. Rockland, MA: EMD Serono, Inc.; 2019.

27. Lunde HMB, Assmus J, Myhr KM, Bo L, Grytten N. Survival and cause of death in multiple sclerosis: a 60-year longitudinal population study. J Neurol Neurosurg Psychiatry. 2017;88(8):621-5. https://doi.org/10.1136/jnnp-2016-315238.

28. Marrie RA, Yu N, Blanchard J, Leung S, Elliott L. The rising prevalence and changing age distribution of multiple sclerosis in Manitoba. Neurology. 2010;74(6):465-71. https://doi. org/10.1212/WNL.0b013e3181cf6ec0.

29. Ploughman M, Beaulieu S, Harris C, Hogan S, Manning OJ, Alderdice PW, et al. The Canadian survey of health, lifestyle and ageing with multiple sclerosis: methodology and initial results. BMJ Open. 2014;4(7):e005718. https://doi.org/10.1136/bmjop en-2014-005718.

30. Baker D, Marta M, Pryce G, Giovannoni G, Schmierer K. Memory B cells are major targets for effective immunotherapy in relapsing multiple sclerosis. EBioMedicine. 2017;16:41-50. https://doi.org/10.1016/j.ebiom.2017.01.042.

31. Leist T, Weissert R. Cladribine: mode of action and implications for treatment of multiple sclerosis. Clin Neuropharmacol. 2011;34(1):28-35. https://doi.org/10.1097/WNF.0b013e3182 $04 \mathrm{~cd} 90$.

32. Dendrou CA, Fugger L, Friese MA. Immunopathology of multiple sclerosis. Nat Rev Immunol. 2015;15(9):545-58. https://doi. org/10.1038/nri3871.

33. Neuhaus O, Archelos JJ, Hartung HP. Immunomodulation in multiple sclerosis: from immunosuppression to neuroprotection. Trends Pharmacol Sci. 2003;24(3):131-8. https://doi. org/10.1016/S0165-6147(03)00028-2.

34. Jelcic I, Al Nimer F, Wang J, Lentsch V, Planas R, Jelcic I, et al. Memory B cells activate brain-homing, autoreactive CD4(+) T cells in multiple sclerosis. Cell. 2018;175(1):85-100. https://doi. org/10.1016/j.cell.2018.08.011(e23).

35. Betaferon [package insert]. Berlin, Germany: Bayer AG; 2018.

36. Goodin DS, Frohman EM, Garmany GP Jr, Halper J, Likosky WH, Lublin FD, et al. Disease modifying therapies in multiple sclerosis: report of the Therapeutics and Technology Assessment Subcommittee of the American Academy of Neurology and the MS Council for Clinical Practice Guidelines. Neurology. 2002;58(2):169-78

37. CenterWatch. Tysabri (natalizumab). https://www.centerwatc h.com/drug-information/fda-approved-drugs/drug/869/tysabrinatalizumab. Accessed 22 Jul 2019.

38. Fontoura P. Monoclonal antibody therapy in multiple sclerosis: paradigm shifts and emerging challenges. MAbs. 2010;2(6):670 81. https://doi.org/10.4161/mabs.2.6.13270.

39. Spelman T, Kalincik T, Jokubaitis V, Zhang A, Pellegrini F, Wiendl $\mathrm{H}$, et al. Comparative efficacy of first-line natalizumab vs IFN-beta or glatiramer acetate in relapsing MS. Neurol Clin Pract. 2016;6(2):102-15. https://doi.org/10.1212/CPJ.00000 00000000227.

40. Singer BA. The role of natalizumab in the treatment of multiple sclerosis: benefits and risks. Ther Adv Neurol Disord. 2017;10(9):327-36. https://doi.org/10.1177/1756285617716002.

41. Eagle T, Stuart F, Chua AS, LaRussa A, Leclaire K, Cook SL, et al. Treatment satisfaction across injectable, infusion, and oral disease-modifying therapies for multiple sclerosis. Mult Scler Relat Disord. 2017;18:196-201. https://doi.org/10.1016/j.msard .2017.10.002.

42. Ocrevus [summary of product characteristics]. GrenzachWyhlen: Roche Pharma AG; 2018.

43. Lemtrada [summary of product characteristics]. Haverhill: Genzyme Ltd.; 2018.

44. Gingele S, Jacobus TL, Konen FF, Hummert MW, Suhs KW, Schwenkenbecher P, et al. Ocrelizumab depletes CD20(+) 
T cells in multiple sclerosis patients. Cells. 2018. https://doi. org/10.3390/cells8010012.

45. Sorensen PS, Blinkenberg M. The potential role for ocrelizumab in the treatment of multiple sclerosis: current evidence and future prospects. Ther Adv Neurol Disord. 2016;9(1):44-52. https://doi. org/10.1177/1756285615601933.

46. Fernandez O. Alemtuzumab in the treatment of multiple sclerosis. J Inflamm Res. 2014;7:19-27. https://doi.org/10.2147/JIR. S38079.

47. Ceronie B, Jacobs BM, Baker D, Dubuisson N, Mao Z, Ammoscato $\mathrm{F}$, et al. Cladribine treatment of multiple sclerosis is associated with depletion of memory B cells. J Neurol. 2018;265(5):1199-209. https://doi.org/10.1007/s0041 5-018-8830-y.

48. Wiendl H. Cladribine-an old newcomer for pulsed immune reconstitution in MS. Nat Rev Neurol. 2017;13(10):573-4. https ://doi.org/10.1038/nrneurol.2017.119.

49. Karussis D, Petrou P. Immune reconstitution therapy (IRT) in multiple sclerosis: the rationale. Immunol Res. 2018;66(6):6428. https://doi.org/10.1007/s12026-018-9032-5.

50. European Medicines Agency. Mavenclad - summary of EPAR. 2017. https://www.ema.europa.eu/en/medicines/human/EPAR/ mavenclad. Accessed 29 Jan 2019.

51. FDA approves new oral treatment for multiple sclerosis [press release]. US Food and Drug Administration; 29 March 2019. https://www.fda.gov/news-events/press-announcements/fdaapproves-new-oral-treatment-multiple-sclerosis. Accessed 11 Feb 2020

52. Saven A, Piro LD. 2-Chlorodeoxyadenosine: a newer purine analog active in the treatment of indolent lymphoid malignancies. Ann Intern Med. 1994;120(9):784-91.

53. Sipe JC, Romine JS, Koziol JA, McMillan R, Zyroff J, Beutler E. Cladribine in treatment of chronic progressive multiple sclerosis. Lancet. 1994;344(8914):9-13.

54. Carson DA, Wasson DB, Taetle R, Yu A. Specific toxicity of 2-chlorodeoxyadenosine toward resting and proliferating human lymphocytes. Blood. 1983;62(4):737-43.

55. Sipe JC. Cladribine for multiple sclerosis: review and current status. Expert Rev Neurother. 2005;5(6):721-7. https://doi. org/10.1586/14737175.5.6.721.

56. Beutler E. Cladribine (2-chlorodeoxyadenosine). Lancet. 1992;340(8825):952-6. https://doi.org/10.1016/01406736(92)92826-2.

57. Carson DA, Kaye J, Seegmiller JE. Lymphospecific toxicity in adenosine deaminase deficiency and purine nucleoside phosphorylase deficiency: possible role of nucleoside kinase(s). Proc Natl Acad Sci USA. 1977;74(12):5677-81.

58. Giovannoni G. Cladribine to treat relapsing forms of multiple sclerosis. Neurotherapeutics. 2017;14(4):874-87. https://doi. org/10.1007/s13311-017-0573-4.

59. Carson DA, Wasson DB, Kaye J, Ullman B, Martin DW Jr, Robins RK, et al. Deoxycytidine kinase-mediated toxicity of deoxyadenosine analogs toward malignant human lymphoblasts in vitro and toward murine L1210 leukemia in vivo. Proc Natl Acad Sci USA. 1980;77(11):6865-9.

60. National Center for Biotechnology Information. PubChem Database. Cladribine, $C I D=20279$. National Institutes of Health. 2019. https://pubchem.ncbi.nlm.nih.gov/compound/Cladribine. Accessed 19 Jun 2019.

61. Toy G, Austin WR, Liao HI, Cheng D, Singh A, Campbell DO, et al. Requirement for deoxycytidine kinase in $\mathrm{T}$ and $\mathrm{B}$ lymphocyte development. Proc Natl Acad Sci USA. 2010;107(12):55516. https://doi.org/10.1073/pnas.0913900107.

62. Toy G, Austin WR, Liao HI, Cheng D, Singh A, Campbell $\mathrm{DO}$, et al. Requirement for deoxycytidine kinase in $\mathrm{T}$ and $\mathrm{B}$ lymphocyte development [supplement]. Proc Natl Acad Sci USA. 2010;107(12):5551-6. https://doi.org/10.1073/pnas.0913900107

63. Sigal DS, Miller HJ, Schram ED, Saven A. Beyond hairy cell: the activity of cladribine in other hematologic malignancies. Blood. 2010;116(16):2884-966. https://doi.org/10.1182/blood-2010-02246140.

64. Comi G, Cook S, Giovannoni G, Rieckmann P, Sorensen PS, Vermersch P, et al. Effect of cladribine tablets on lymphocyte reduction and repopulation dynamics in patients with relapsing multiple sclerosis. Mult Scler Relat Disord. 2019;29:168-74. https://doi.org/10.1016/j.msard.2019.01.038.

65. Giovannoni G, Comi G, Cook S, Rammohan K, Rieckmann P, Soelberg Sorensen P, et al. A placebo-controlled trial of oral cladribine for relapsing multiple sclerosis. N Engl J Med. 2010;362(5):416-26. https://doi.org/10.1056/NEJMoa0902533.

66. Giovannoni G, Soelberg Sorensen P, Cook S, Rammohan K, Rieckmann P, Comi G, et al. Safety and efficacy of cladribine tablets in patients with relapsing-remitting multiple sclerosis: results from the randomized extension trial of the CLARITY study. Mult Scler. 2018;24(12):1594-604. https://doi. org/10.1177/1352458517727603.

67. Stuve O, Soelberg Soerensen P, Leist T, Giovannoni G, Hyvert Y, Damian D, et al. Effects of cladribine tablets on lymphocyte subsets in patients with multiple sclerosis: an extended analysis of surface markers. Ther Adv Neurol Disord. 2019;12:1756286419854986. https://doi.org/10.1177/17562 86419854986

68. Beutler E, Sipe JC, Romine JS, Koziol JA, McMillan R, Zyroff J. The treatment of chronic progressive multiple sclerosis with cladribine. Proc Natl Acad Sci USA. 1996;93(4):1716-20. https ://doi.org/10.1073/pnas.93.4.1716.

69. Romine JS, Sipe JC, Koziol JA, Zyroff J, Beutler E. A doubleblind, placebo-controlled, randomized trial of cladribine in relapsing-remitting multiple sclerosis. Proc Assoc Am Physicians. 1999;111(1):35-44.

70. Terranova N, Hicking C, Dangond F, Munafo A. Effects of postponing treatment in the second year of cladribine administration: Clinical trial simulation analysis of absolute lymphocyte counts and relapse rate in patients with relapsing-remitting multiple sclerosis. Clin Pharmacokinet. 2019;58(3):325-33. https://doi. org/10.1007/s40262-018-0693-y.

71. Sørensen PS, Centonze D, Giovannoni G, Montalban X, Selchen D, Vermersch P, et al. Expert opinion on the use of cladribine tablets in clinical practice. Ther Adv Neurol Disord. 2020;13:1756286420935019. https://doi.org/10.1177/17562 86420935019 .

72. Hermann R, Karlsson MO, Novakovic AM, Terranova N, Fluck $\mathrm{M}$, Munafo A. The clinical pharmacology of cladribine tablets for the treatment of relapsing multiple sclerosis. Clin Pharmacokinet. 2019;58(3):283-97. https://doi.org/10.1007/s4026 2-018-0695-9.

73. Savic RM, Novakovic AM, Ekblom M, Munafo A, Karlsson MO. Population pharmacokinetics of cladribine in patients with multiple sclerosis. Clin Pharmacokinet. 2017;56(10):1245-53. https ://doi.org/10.1007/s40262-017-0516-6.

74. Giovannoni G, Galazka A, Schick R, Leist T, Comi G, Montalban $\mathrm{X}$, et al. Pregnancy outcomes during the clinical development program of cladribine in multiple sclerosis: an integrated analysis of safety. Drug Saf. 2020;43(7):635-43. https://doi.org/10.1007/ s40264-020-00948-x.

75. Singh V, Voss EV, Benardais K, Stangel M. Effects of 2-chlorodeoxyadenosine (Cladribine) on primary rat microglia. J Neuroimmune Pharmacol. 2012;7(4):939-50. https://doi.org/10.1007/ s11481-012-9387-7. 
76. Kearns CM, Blakley RL, Santana VM, Crom WR. Pharmacokinetics of cladribine (2-chlorodeoxyadenosine) in children with acute leukemia. Cancer Res. 1994;54(5):1235-9.

77. Liliemark J. The clinical pharmacokinetics of cladribine. Clin Pharmacokinet. 1997;32(2):120-31. https://doi. org/10.2165/00003088-199732020-00003.

78. Rejdak K, Stelmasiak Z, Grieb P. Cladribine induces long lasting oligoclonal bands disappearance in relapsing multiple sclerosis patients: 10-year observational study. Mult Scler Relat Disord. 2019;27:117-20. https://doi.org/10.1016/j.msard.2018.10.006.

79. McDonald WI, Compston A, Edan G, Goodkin D, Hartung HP, Lublin FD, et al. Recommended diagnostic criteria for multiple sclerosis: guidelines from the international panel on the diagnosis of multiple sclerosis. Ann Neurol. 2001;50(1):121-7.

80. Fazekas F, Barkhof F, Filippi M, Grossman RI, Li DK, McDonald WI, et al. The contribution of magnetic resonance imaging to the diagnosis of multiple sclerosis. Neurology. 1999;53(3):448-56.

81. Rammohan K, Giovannoni G, Comi G, Cook S, Rieckmann P, Soelberg Sorensen P, et al. Cladribine tablets for relapsingremitting multiple sclerosis: efficacy across patient subgroups from the phase III CLARITY study. Mult Scler Relat Disord. 2012;1(1):49-544. https://doi.org/10.1016/j.msard.2011.08.006.

82. Lorscheider J, Buzzard K, Jokubaitis V, Spelman T, Havrdova E, Horakova D, et al. Defining secondary progressive multiple sclerosis. Brain. 2016;139(Pt 9):2395-405. https://doi.org/10.1093/ brain/aww173.

83. Kappos L, Bar-Or A, Cree BAC, Fox RJ, Giovannoni G, Gold $\mathrm{R}$, et al. Siponimod versus placebo in secondary progressive multiple sclerosis (EXPAND): a double-blind, randomised, phase 3 study. Lancet. 2018;391(10127):1263-73. https://doi. org/10.1016/S0140-6736(18)30475-6.

84. Kapoor R, Ho PR, Campbell N, Chang I, Deykin A, Forrestal $\mathrm{F}$, et al. Effect of natalizumab on disease progression in secondary progressive multiple sclerosis (ASCEND): a phase 3, randomised, double-blind, placebo-controlled trial with an openlabel extension. Lancet Neurol. 2018;17(5):405-15. https://doi. org/10.1016/S1474-4422(18)30069-3.

85. Lublin FD, Reingold SC, Cohen JA, Cutter GR, Sorensen PS, Thompson AJ, et al. Defining the clinical course of multiple sclerosis: the 2013 revisions. Neurology. 2014;83(3):278-86. https ://doi.org/10.1212/WNL.0000000000000560.

86. Cook S, Rammohan K, Rieckmann P, Soelberg Sorensen P, Vermersch $\mathrm{P}$, Hicking $\mathrm{C}$ et al. Slowing of disability progression based on 6-month confirmed EDSS in patients with relapsingremitting multiple sclerosis (RRMS) treated with cladribine tablets in the CLARITY study: a post-hoc subgroup analysis. American Academy of Neurology (AAN); 15-21 April 2016; Vancouver, BC: 1510.

87. Giovannoni G, Cook S, Rammohan K, Rieckmann P, Sorensen PS, Vermersch P, et al. Sustained disease-activity-free status in patients with relapsing-remitting multiple sclerosis treated with cladribine tablets in the CLARITY study: a post-hoc and subgroup analysis. Lancet Neurol. 2011;10(4):329-37. https://doi. org/10.1016/S1474-4422(11)70023-0.

88. Giovannoni G, Soelberg Sorensen P, Cook S, Rammohan KW, Rieckmann P, Comi G, et al. Efficacy of cladribine tablets in high disease activity subgroups of patients with relapsing multiple sclerosis: a post hoc analysis of the CLARITY study. Mult Scler. 2019;25(6):819-27. https://doi.org/10.1177/1352458518771875.

89. Comi G, Cook SD, Giovannoni G, Rammohan K, Rieckmann P, Sorensen PS, et al. MRI outcomes with cladribine tablets for multiple sclerosis in the CLARITY study. J Neurol. 2013;260(4):1136-46. https://doi.org/10.1007/s0041 5-012-6775-0.

90. De Stefano N, Giorgio A, Battaglini M, De Leucio A, Hicking $\mathrm{C}$, Dangond F, et al. Reduced brain atrophy rates are associated with lower risk of disability progression in patients with relapsing multiple sclerosis treated with cladribine tablets. Mult Scler. 2018;24(2):222-6. https://doi.org/10.1177/1352458517690269.

91. Comi G, Cook S, Rammohan K, Soelberg Sorensen P, Vermersch P, Adeniji AK, et al. Long-term effects of cladribine tablets on MRI activity outcomes in patients with relapsingremitting multiple sclerosis: the CLARITY Extension study. Ther Adv Neurol Disord. 2018;11:1756285617753365. https:// doi.org/10.1177/1756285617753365.

92. Havrdova E, Arnold DL, Cohen JA, Hartung HP, Fox EJ, Giovannoni G, et al. Alemtuzumab CARE-MS I 5-year follow-up: durable efficacy in the absence of continuous MS therapy. Neurology. 2017;89(11):1107-16. https://doi.org/10.1212/WNL.00000 00000004313.

93. Giovannoni G, Keller B, Jack D. Durability of NEDA-3 status in patients with relapsing multiple sclerosis receiving cladribine tablets: CLARITY extension. Berlin, Germany: European Committee for Treatment and Research in Multiple Sclerosis (ECTRIMS); 10-12 October 2018. p 894.

94. Leist TP, Comi G, Cree BA, Coyle PK, Freedman MS, Hartung $\mathrm{HP}$, et al. Effect of oral cladribine on time to conversion to clinically definite multiple sclerosis in patients with a first demyelinating event (ORACLE MS): a phase 3 randomised trial. Lancet Neurol. 2014;13(3):257-67. https://doi.org/10.1016/S1474 -4422(14)70005-5.

95. Polman $\mathrm{CH}$, Reingold SC, Banwell B, Clanet M, Cohen JA, Filippi M, et al. Diagnostic criteria for multiple sclerosis: 2010 revisions to the McDonald Criteria. Ann Neurol. 2011;69(2):292-302. https://doi.org/10.1002/ana.22366.

96. Polman CH, Reingold SC, Edan G, Filippi M, Hartung HP, Kappos L, et al. Diagnostic criteria for multiple sclerosis: 2005 revisions to the "McDonald Criteria". Ann Neurol. 2005;58(6):840 6. https://doi.org/10.1002/ana.20703.

97. Freedman MS, Leist TP, Comi G, Cree BA, Coyle PK, Hartung HP, et al. The efficacy of cladribine tablets in CIS patients retrospectively assigned the diagnosis of MS using modern criteria: results from the ORACLE-MS study. Mult Scler J Exp Transl Clin. 2017;3(4):2055217317732802. https://doi. org/10.1177/2055217317732802.

98. Thompson AJ, Banwell BL, Barkhof F, Carroll WM, Coetzee T, Comi G, et al. Diagnosis of multiple sclerosis: 2017 revisions of the McDonald criteria. Lancet Neurol. 2018;17(2):162-73. https ://doi.org/10.1016/S1474-4422(17)30470-2.

99. Lee DH, Peschke M, Utz KS, Linker RA. Diagnostic value of the $2017 \mathrm{McDonald}$ criteria in patients with a first demyelinating event suggestive of relapsing-remitting multiple sclerosis. Eur J Neurol. 2019;26(3):540-5. https://doi.org/10.1111/ene.13853.

100. Montalban X, Leist TP, Cohen BA, Moses H, Campbell J, Hicking $\mathrm{C}$, et al. Cladribine tablets added to IFN-beta in active relapsing MS: the ONWARD study. Neurol Neuroimmunol Neuroinflamm. 2018;5(5):e477. https://doi.org/10.1212/NXI.00000 00000000477.

101. Miret M WJ, Gedney L, et al, editor. Evaluation of the longterm safety of cladribine tablets in multiple sclerosis design of PREMIERE, a prospective, observational, 8-year safety registry. Berlin, Germany: European Neurological Society (ENS); 19-23 June 2010.

102. Cook S, Leist T, Comi G, Montalban X, Giovannoni G, Nolting A, et al. Safety of cladribine tablets in the treatment of patients with multiple sclerosis: an integrated analysis. Mult Scler Relat Disord. 2019;29:157-67. https://doi.org/10.1016/j.msard .2018.11.021.

103. Cook S, Giovannoni G, Leist T, Syed S, Nolting A, Schick R. Updated safety analysis of cladribine tablets in the treatment of patients with multiple sclerosis. Berlin, Germany: European 
Committee for Treatment and Research in Multiple Sclerosis (ECTRIMS); 10-12 October 2018. p 875.

104. Pakpoor J, Disanto G, Altmann DR, Pavitt S, Turner BP, Marta $\mathrm{M}$, et al. No evidence for higher risk of cancer in patients with multiple sclerosis taking cladribine. Neurol Neuroimmunol Neuroinflamm. 2015;2(6):e158. https://doi.org/10.1212/NXI.00000 00000000158.

105. Cook S, Giovannoni G, Leist T, Syed S, Nolting A, Damian D et al. Updated safety analysis of cladribine tablets in the treatment of patients with multiple sclerosis. American Academy of Neurology (AAN); 4-10 May 2019; Philadelphia, PA: P2-048.

106. European Network of Centres for Pharmacoepidemiology and Pharmacovigilance. Long term, prospective, observational cohort study evaluating the safety profile in patients with highly active relapsing multiple sclerosis (RMS) newly started on oral cladribine (CLARION). Registration Number: EUPAS24484. European Medicines Agency. https://www.encepp.eu/encepp/ viewResource.htm;jsessionid=RRDIMPSP8OTBkioaK0xjVIqbv MSXLwQLWzCzzwl1SXQsqQBB6TH9!562573046?id=25122 . Accessed 15 Jul 2019.

107. Mavenclad [product information]. Zug: Merck (Schweiz) AG; 2019.

108. Mavenclad [product monograph]. Mississauga, ON: EMD Serono, Inc.; 2017.

109. Mavenclad [product information]. Frenchs Forest, NSW: Merck Serono Australia; 2019.

110. Shirani A, Okuda DT, Stuve O. Therapeutic advances and future prospects in progressive forms of multiple sclerosis. Neurotherapeutics. 2016;13(1):58-69. https://doi.org/10.1007/s1331 1-015-0409-z.

111. PR Newswire. Up to 10-years of follow-up data reaffirm safety profile of investigational cladribine tablets. EMD Serono, Inc. 2018. https://www.prnewswire.com/news-releases/up-to10-years-of-follow-up-data-reaffirm-safety-profile-of-investigat ional-cladribine-tablets-873347245.html. Accessed 15 Jul 2019.

112. Baker D, Herrod SS, Alvarez-Gonzalez C, Giovannoni G, Schmierer K. Interpreting lymphocyte reconstitution data from the pivotal Phase 3 trials of alemtuzumab. JAMA Neurol. 2017;74(8):961-9. https://doi.org/10.1001/jamaneurol .2017 .0676

113. Cossburn M, Pace AA, Jones J, Ali R, Ingram G, Baker K, et al. Autoimmune disease after alemtuzumab treatment for multiple sclerosis in a multicenter cohort. Neurology. 2011;77(6):573-9. https://doi.org/10.1212/WNL.0b013e318228bec5.

114. Glatopa [package insert]. Princeton, NJ: Sandoz Inc.; 2018.

115. Hussain RZ, Hayardeny L, Cravens PC, Yarovinsky F, Eagar TN, Arellano B, et al. Immune surveillance of the central nervous system in multiple sclerosis-relevance for therapy and experimental models. J Neuroimmunol. 2014;276(1-2):9-17. https:// doi.org/10.1016/j.jneuroim.2014.08.622.

116. Boyko AN, Boyko OV. Cladribine tablets' potential role as a key example of selective immune reconstitution therapy in multiple sclerosis. Degener Neurol Neuromuscul Dis. 2018;8:35-44. https ://doi.org/10.2147/DNND.S161450.

117. Nicholas J, Edwards NC, Edwards RA, Dellarole A, Manca L, Harlow DE et al. Predictors of non-adherence among patients with multiple sclerosis newly initiating once- or twice-daily oral disease-modifying drugs. International Society for Pharmacoeconomics and Outcomes Research (ISPOR); 18-22 May 2019; New Orleans, LA: PND91.

118. Peyrot M, Rubin RR, Kruger DF, Travis LB. Correlates of insulin injection omission. Diabetes Care. 2010;33(2):240-5. https://doi. org/10.2337/dc09-1348.

119. Tintore M, Alexander M, Costello K, Duddy M, Jones DE, Law $\mathrm{N}$, et al. The state of multiple sclerosis: current insight into the patient/health care provider relationship, treatment challenges, and satisfaction. Patient Prefer Adherence. 2017;11:33-45. https ://doi.org/10.2147/PPA.S115090.

120. Crawford A, Jewell S, Mara H, McCatty L, Pelfrey R. Managing treatment fatigue in patients with multiple sclerosis on longterm therapy: the role of multiple sclerosis nurses. Patient Prefer Adherence. 2014;8:1093-9. https://doi.org/10.2147/PPA.S6733 4.

121. Menzin J, Caon C, Nichols C, White LA, Friedman M, Pill MW. Narrative review of the literature on adherence to diseasemodifying therapies among patients with multiple sclerosis. J Manag Care Pharm. 2013;19(1 Suppl A):S24-S40. https://doi. org/10.18553/jmcp.2013.19.s1.S24.

122. Christensen LF, Broom AD, Robins MJ, Bloch A. Synthesis and biological activity of selected 2,6-disubstituted-(2-deoxy$\alpha$-and- $\beta$-D-erythro-pentofuranosyl)purines. J Med Chem. 1972;15(7):735-9. https://doi.org/10.1021/jm00277a010.

123. EMD Serono, Inc. Prospective observational long-term safety registry of multiple sclerosis patients who have participated in cladribine clinical trials (PREMIERE). ClinicalTrials.gov. 2018. https://clinicaltrials.gov/ct2/show/NCT01013350. Accessed 15 Jul 2019.

124. US Food and Drug Administration. FDA Approved Drug Products-Leustatin. 1993. https://www.accessdata.fda.gov/scripts/ cder/daf/index.cfm?event=overview.process \&ApplNo=020229. Accessed 15 Jul 2019.

125. MS Research Australia. Relapsing MS treatment cladribine on the comeback. 2017. https://msra.org.au/news/relapsing-ms-treat ment-cladribine-comeback/. Accessed 15 Jul 2019.

126. Merck Serono Europe Limited withdraws its marketing authorisation application for Movectro (cladribine) [press release]. European Medicines Agency; 11 February 2011. https://www. ema.europa.eu/en/documents/press-release/merck-serono-europ e-limited-withdraws-its-marketing-authorisation-applicatio n-movectro-cladribine_en.pdf. Accessed 11 Feb 2020.

127. FDA grants priority review to cladribine tablets for the treatment of relapsing forms of MS [press release]. EMD Serono, Inc.; 28 July 2010. https://media.emdserono.com/2010-0728-EMD-SERONO-INC-FDA-GRANTS-PRIORITY-REVIE W-TO-CLADRIBINE-TABLETS-FOR-THE-TREATMENTOF-RELAPSING-FORMS-OF-MS. Accessed 15 Jul 2019.

128. PR Newswire. EMD Serono receives complete response letter from FDA on cladribine tablets new drug application. 2011. https://www.prnewswire.com/news-releases/emd-serono-recei ves-complete-response-letter-from-fda-on-cladribine-tabletsnew-drug-application-117220383.html. Accessed 15 Jul 2019.

129. The Pharma Letter. EMA accepts Merck's MAA for cladribine tablets in multiple sclerosis. 2016. https://www.thepharmaletter .com/article/ema-accepts-merck-s-maa-for-cladribine-tablet-inmultiple-sclerosis. Accessed 15 Jul 2019.

130. European Commission grants approval for mavenclad (cladribine tablets) [press release]. Merck KGaA; 25 August 2017. https ://www.emdgroup.com/en/news/mavenclad-25-08-2017.html. Accessed 15 Jul 2019.

131. FDA accepts file for cladribine tablets as potential treatment for relapsing forms of multiple sclerosis [press release]. EMD Serono, Inc.; 30 July 2018. https://media.emdserono.com/FDAAccepts-File-for-Cladribine-Tablets. Accessed 11 Feb 2020.

132. Soelberg-Sorensen P, Dangond F, Hicking C, Giovannoni G. Long-term lymphocyte counts in patients with relapsing-remitting multiple sclerosis (RRMS) treated with cladribine tablets $3.5 \mathrm{mg} / \mathrm{kg}$ : total lymphocytes, b and t cell subsets. Paris, France: European Committee for Treatment and Research in Multiple Sclerosis (ECTRIMS); 25-28 October 2017. 